\title{
Le ban et l'arrière-ban de Bretagne : un service féodal à l'épreuve des troubles de religion (vers 1550-vers 1590)
}

The ban and the arrière-ban in Brittany: putting a feudal service to the test of religious unrest (c.1550-c.1590)

\section{Antoine Rivault}

\section{OpenEdition}

Journals

Édition électronique

URL : http://journals.openedition.org/abpo/2565

DOI : $10.4000 / a b p o .2565$

ISBN : 978-2-7535-2782-9

ISSN : 2108-6443

Éditeur

Presses universitaires de Rennes

Édition imprimée

Date de publication : 30 mars 2013

Pagination : 59-96

ISBN : 978-2-7535-2780-5

ISSN : 0399-0826

Référence électronique

Antoine Rivault, « Le ban et l'arrière-ban de Bretagne : un service féodal à l'épreuve des troubles de religion (vers 1550-vers 1590) », Annales de Bretagne et des Pays de l'Ouest [En ligne], 120-1 | 2013, mis en ligne le 30 mars 2015, consulté le 01 mai 2019. URL : http://journals.openedition.org/abpo/2565 ; DOI : $10.4000 / a b p o .2565$ 


\title{
Le ban et l'arrière-ban de Bretagne : un service féodal à l'épreuve des troubles de religion (vers 1550-vers 1590)
}

\author{
Antoine RIVAULT \\ doctorant, Université Rennes 2, CERHIO-UMR 6258
}

"Ils ne rendent guère de service militaire. Cependant, ceux qui font partie des troupes auxiliaires sont soumis au ban du roi et paient de leurs deniers leur entretien sous les armes. Les autres, n'étant pas suffisamment aguerris, ne sont convoqués que très rarement et seulement en cas de nécessité de salut public ${ }^{1}$. " Ainsi s'exprime Étienne Vitelli pour désigner les Bretons en 1567, soulignant par ces mots la faible représentation de ceux-ci au sein de l'armée royale mais la contribution effective de certains hommes au service banal qui assure le maintien de l'ordre dans la province.

Un certain nombre d'institutions féodales connaissent au cours du $\mathrm{XVI}^{\mathrm{e}}$ siècle des adaptations qui prolongent la " genèse médiévale " de la France moderne ${ }^{2}$. Parmi celles-ci, l'ancien service de l'ost militaire dû aux rois de France subit une grande vague de législation et de réglementation au cours des $\mathrm{XV}^{\mathrm{e}}$ et $\mathrm{XVI}^{\mathrm{e}}$ siècles, ce qui en fait une véritable "institution militaire " à part entière, une " réserve organisée ${ }^{3}$ ". On parle alors du ban et de l'arrière-ban du royaume. Lucien Febvre rappelle bien, à propos de la guerre, que c'est la " grande occupation, [le] gros souci du noble. Combattre reste à ses yeux, comme par le passé, sa vraie, son unique fonction ${ }^{4}$ ". Dès lors, le service féo-

1. VITELLI, Étienne, Commentaires sur la guerre civile de France, 1567, Édition et traduction par Anne LOMBARD-JOURDAN, en collaboration avec Marc H. SMITH, études et rencontres de l'École des chartes, vol. 17, Paris, 2002, p. 103. «In militiam autem vix proficiscuntur. Qui tamen sunt e turmis auxiliaribus edicto regio coguntur suisque pecuniis castrenses impensas sustinent. Reliqui raro admodum, quia non sunt satis experti milites, nisi summo Reipub. tempore convocantur."

2. Mollat, Michel, Genèse médiévale de la France moderne. XIVe-XVe siècles, Paris, Éd. du Seuil, 1977, $301 \mathrm{p}$.

3. Contamine, Philippe, Guerre, État et société à la fin du Moyen Âge, Études sur les armées des rois de France (1337-1494), Paris-La Haye, 1972, p. 367.

4. FeBvRE, Lucien, Philippe II et la Franche-Comté, Paris, Flammarion, 1970, p. 227. 
dal reste un cadre d'expression militaire de la noblesse. Michel Nassiet a bien montré l'importance de cette institution et des sources qu'elle a engendrées pour appréhender une histoire de la noblesse au XvI ${ }^{\mathrm{e}}$ siècle $^{5}$. Mais qu'en est-il du service lui-même ? Le cas breton est particulier car l'État royal s'est vu dans la nécessité d'y appliquer d'importantes réformes pendant les troubles de religion. Cela est-il dû au manque de prestige de l'institution ou alors à une volonté croissante de l'État d'augmenter son contrôle sur la noblesse en armes, tout en adaptant le service à la guerre moderne ? Quels sont les individus qui peuvent servir et quels sont ceux qui le désirent vraiment ? La question des moyens financiers des soldats est centrale mais il ne faut pas oublier tous les enjeux sociaux relatifs au port des armes. Dès lors, quelles sont les attitudes du pouvoir royal face aux nobles incapables de servir, mais aussi aux non-nobles qui le peuvent?

L'accent a souvent été mis par les historiens sur les compagnies d'ordonnance et les premiers cadres de l'armée permanente comme structurants pour l'État militaire moderne. Ainsi, les provinces-frontières au nord et à l'est du royaume comme la Picardie ou la Champagne qui mobilisent l'essentiel de l'armée permanente française ont largement été étudiées ${ }^{6}$. La Bretagne, longtemps à l'écart de la " guerre guerroyeuse ${ }^{7}$ " au cours des guerres de Religion mobilise également la majorité de ses compagnies d'ordonnance à ses marches et au-delà. De plus - comme le souligne bien Vitelli - c'est la province du royaume la moins pourvue en compagnies royales ${ }^{8}$. Cette situation nous permet de prendre pleinement conscience du rôle militaire de l'arrière-ban, devenu localement - pour un temps - seul garant de l'ordre public. Face aux diverses menaces (anglo-flamandes, espagnoles, calvinistes), le service banal serait-il plus effectif qu'on ne voudrait le croire?

Pour répondre à ces questions il est nécessaire d'observer le mouvement réformateur qui aboutit à un service propre à la province, puis d'analyser les organisations et les logiques de commandement militaire de celui-ci. Enfin, il faudra se pencher sur le poids militaire du service en s'interrogeant sur l'effectivité et l'efficacité d'un service féodal pendant les troubles de religion.

5. NASSIET, Michel, "La noblesse en France au XVI ${ }^{\mathrm{e}}$ siècle d'après l'arrière-ban ", Revue d'Histoire Moderne et Contemporaine, 46-1, janvier-mars 1999, p. 86-116.

6. BoURQUIN, Laurent, Noblesse seconde et pouvoir en Champagne, aux XVI et XVII siècles, Paris, Publications de la Sorbonne, 1995. PotTER, David, War and Government in the French Provinces: Picardy, 1470-1560, Cambridge University Press, 1993.

7. L'expression est de Michel CASSAN dans "Seigneurs et communautés villageoises au temps des guerres de Religion ", Revue historique, 618, avril-juin 2001, p. 449.

8. James Wood compte trois compagnies de Bretagne pour les 91 du royaume en 1566 (Wood, James, The King's Army. Warfare, Soldiers, and Society during the Wars of Religion in France, 1562-1576, Cambridge, 1996, p. 288). 


\section{Un besoin de réformes : entretenir l'idéal nobiliaire}

L'arrière-ban est un service militaire imposé à tous les détenteurs de fiefs nobles. Il remonte à l'ancienne pratique médiévale de la levée de l'ost seigneurial. Il s'agit de "l'impôt du sang " de la noblesse ${ }^{9}$. En effet, le monarque dispose d'un pouvoir de ban pour convoquer ses vassaux aux campagnes militaires. On distingue les vassaux directs et les arrière-vassaux ou vavasseurs, c'est-à-dire littéralement le ban et l'arrière-ban, mais le terme d'arrière-ban devient englobant $a u \mathrm{XvI}^{\mathrm{e}}$ siècle et ne désigne plus qu'une seule et même institution militaire ${ }^{10}$. Au XVI ${ }^{\mathrm{e}}$ siècle, seul un petit nombre d'individus nobles peut servir dans les compagnies d'ordonnance, et nous verrons qu'en Bretagne, l'arrière-ban apparaît comme un cadre d'expression militaire de la noblesse. Car celle-ci fonde sa situation sociale sur le monopole des armes ${ }^{11}$.

\section{Genèse du service au $X V I^{e}$ siècle}

C'est François I $^{\text {er }}$ qui réaffirme le temps du service des feudataires par ordonnance en 1545. Le service extérieur au royaume est toujours de 40 jours (sans compter l'aller-retour), et le service (ou quartier) effectué à l'intérieur du royaume est désormais établi à trois mois ${ }^{12}$. Pendant les guerres de Religion, le service trimestriel est toujours d'actualité comme le relève François de la Noue :

"Anciennement les arrierebans n'estoient tenus de servir le roy que six sepmaines, et seulement pour la defense du royaume [...] mais par les ordonnances faites depuis, il semble qu'on ait allongé le terme jusques à trois mois, tant pour aller où sont les affaires, que pour y sejourner, en quoy il y a quelque raison pour l'estendüe du royaume ${ }^{13}$."

Mais il semble que le service de l'arrière-ban en Bretagne est limité à la seule défense de la province. En effet, en 1562, le duc de Montpensier (alors gouverneur de l'Anjou, Maine et Touraine) appelle à l'aide le gouverneur de Bretagne, Jean de Brosse, duc d'Étampes et comte de Penthièvre, pour maintenir la paix dans son gouvernement et à ce titre, lui demande

9. DRÉVILLON, Hervé, L'Impôt du sang. Le métier des armes sous Louis XIV, Paris, Taillandier, 2005, 526 p.

10. Michel Nassiet utilise donc la seule dénomination d'arrière-ban ( "La noblesse en France... ", op. cit., p. 86), et suit Gilles de Gouberville qui ne fait plus la distinction (Gouberville, Le Journal du sire de Gouberville, Bricquebosq, les Éd. des Champs, 1993, 4 volumes).

11. Ibidem.

12. LEBEURIER, Rôle des taxes de l'arrière-ban du baillage d'Évreux, en 1562, avec une introduction sur l'histoire et l'organisation du ban et de l'arrière-ban, Paris, Dumoulin, 1861, p. 43. Art. 9 : « Le service du dit arrière-ban sera de trois mois dedans le royaume, ou de quarante jours hors d'iceluy. "

13. La NouE, François de, Discours politiques et militaires, édition établie par F. E. SuTcLIFFe, Genève, Droz, 1967, p. 268. Voir également pour la Bretagne, Arch. dép. d'Ille-et-Vilaine, C 2860, p. 3 : " durant les troys moys que lesdits ban et arrière ban nous soit tenuz servir a lever $[\ldots]$ en icelluy pais. " 
" trois ou quatre canons garniz de boulletz avecques quatre compaignies de gens de pied ${ }^{14}$ ". Le gouverneur de Bretagne est également sollicité pour combattre les huguenots de Montgomery en Normandie mais le duc d'Étampes répond que c'est sa principale force et qu'il ne peut les mobiliser hors de la province ${ }^{15}$. L'arrière-ban reste donc sous le commandement du lieutenant général Georges de Bueil, sieur de Bouillé, pour la défense de la province contre " les Anglois " pendant que le duc d'Étampes et son neveu le vicomte de Martigues partent rejoindre l'armée royale avec des troupes du roi ${ }^{16}$.

Suivant leur fortune individuelle, les feudataires sont assignés à une fonction ou à un service particulier et doivent fournir les armes et les équipements y correspondant. Dans l'importance de leurs revenus pris en compte, ne sont compris que les revenus nobles, c'est-à-dire les rentes foncières et seigneuriales. Des roturiers possédant des biens nobles sont donc concernés par ce service ${ }^{17}$. En effet, devant la multiplication de roturiers possédant des fiefs en Bretagne malgré les diverses interdictions ducales, puis royales, à ce sujet, François Ier légalise la situation bretonne en demandant en contrepartie le service de ces feudataires à l'arrièreban ${ }^{18}$. Cependant, les acquisitions de terres nobles sont surveillées de très près et limitées dans leur valeur. Ainsi, en 1552, dans les dix lettres d'autorisation d'acquisition les biens nobles ne dépassent pas la valeur de 500 livres de rentes (la moyenne est de 200 livres d'acquisition) ${ }^{19}$. Certains roturiers ont des moyens importants et peuvent même venir grossir les rangs des cavaliers, ce qui constitue un avantage pour pallier la pauvreté de certains nobles incapables de fournir un service équestre ${ }^{20}$.

14. Lettre du duc de Montpensier au duc d'Étampes,, Angers 16 juin 1562, citée dans LUBLINSKAYA, Aleksandra Dmitrievna, Documents pour servir à l'histoire des guerres civiles en France (1561-1563), Moscou et Leningrad, 1962, p. 67.

15. Lettre du duc d'Étampes à Catherine de Médicis, Nantes, 17-19 juin 1562 (Ibid., p. 69).

16. Lettre du duc d'Étampes à Antoine de Bourbon, Nantes, 26 juin 1562 : « Et se delaissant avec monsieur de Bouillé les arierebans et autres forces ordinaires du pays a la garde d'icelluy " (Ibid., p. 77).

17. Montre générale de l'évêché de Saint-Brieuc, le 10 juillet 1569, " ensuivent les noms de ceux qui se presantent à cause de fiefs nobles qu'ils ont et tiennent " (30 feudataires) (Arch. dép. des Côtes-d'Armor, C 7, f 28 et suivants).

18. Archives Nationales (désormais Arch. nat.), K 1152, n $31, \mathrm{f}^{\circ} 19-23$. Ordonnance donnée à Vateville le 10 mai 1535 : " Mandement au sieur de Châteaubriang gouverneur de Bretagne, d'exiger de tous roturiers, même gens d'Eglise et de Robe, la déclaration des terres nobles par eux acquises dans le Duché, de composer avec ceux qui l'auront faite et d'opérer saisie sur les autres ». Sur les interdictions antérieures : interdictions du 27 mai 1451 par le duc Pierre II puis confirmée par provision le 11 avril 1518 (MORICE, Mémoires pour servir de preuves à l'histoire ecclésiastique et civile de Bretagne, Paris, 1746, t. II, col. 1589-1590 (désormais MoricE, Preuves).

19. Arch. nat., JJ 261/2, f $190 \mathrm{v}^{\circ}, 214 \mathrm{v}^{\circ}, 216$ et v $\mathrm{v}^{\circ}, 227 \mathrm{v}^{\circ}-228,278,295 \mathrm{v}^{\circ}-296,362 \mathrm{v}^{\circ}-363$, 363 et $v^{\circ}$, et Arch. dép. de Loire-Atlantique, B 53, 265 et vº. Pour l'année 1551, il n'y a guère que 13 lettres d'autorisation (Arch. dép. de Loire-Atlantique, B 53, 165 et suivants ; Arch. nat., $J J 261 / 1, f^{\circ} 119 \mathrm{v}^{\circ}-120,191$ et $\mathrm{v}^{\circ}$ ).

20. Comme « Jacques Cillart, sieur de Coueslagat, homme à cheval, à cause de ses terres nobles ", montre des gentilshommes de l'évêché de Vannes en garnison à Belle-Île en 1553 (Morice, Preuves, t. III, col. 1094). 
D'autre part, la convocation n'est pas personnelle, mais réelle ${ }^{21}$; c'est-àdire que les feudataires qui ne sont pas en mesure d'effectuer le service militaire comme les vieillards, les veuves, les héritières ou les héritiers mineurs, peuvent envoyer des remplaçants en leur nom au service de l'arrière-ban ${ }^{22}$. François de La Noue dépeint ces inefficaces et encombrants remplaçants en parlant " de gros valets, ayant un pied de barbe, qui en un jour mangent demy mouton, lesquels marchent pour leurs maistres ${ }^{23}$ ". Cependant, Henri II limita cette disposition par l'ordonnance du 16 janvier 1557. Désormais la substitution ne fut tolérée que du fils pour le père et du frère pour son frère ${ }^{24}$.

Dès les années 1445-1449, parallèlement à l'instauration des premières instances permanentes de l'armée, Charles VII procède à une vaste réorganisation du service. Des commissaires sont désignés pour établir des registres des feudataires disponibles avec la valeur de leur fief pour déterminer leurs obligations au sein de l'arrière-ban. Ainsi, en 1557, lors d'une montre du ban et de l'arrière-ban de Rennes, les 257 gentilshommes appelés font des "déclarations " de tous leurs revenus et rentes nobles ${ }^{25}$. Ceux qui sont astreints à ce service doivent être présents à la " montre ", c'est-à-dire une revue où leur équipement et leurs armes sont inspectés, tout comme les compagnies d'ordonnance, et où les gentilshommes sont organisés en compagnies spécialisées selon leurs compétences et fonctions militaires. Les feudataires sont à l'origine mentionnés selon leur paroisse de résidence. Avec ces registres, les montres peuvent être tenues beaucoup plus régulièrement qu'auparavant. En 1534, François Irer détermine la fréquence des montres, celles-ci doivent désormais rassembler les gentilshommes d'un évêché au moins une fois par $\mathrm{an}^{26}$. De plus, des montres préparatoires mesurent la bonne adéquation des revenus nobles avec le service du feudataire. L'équipement varie également selon les revenus du feudataire. Il est intéressant de noter les changements d'exigences en qualité d'armement et d'équipement pour ceux qui servent dans l'arrière-ban : le corselet (sorte de cuirasse) et le morion (casque) remplacent la salade et la brigandine

21. NASSIET, Michel, " La noblesse en France..., op. cit., p. 88.

22. Voici un exemple parmi les nombreux disponibles : "Jehan Joue pour la dame de Hencouet ", lors de la montre de cinquante arquebusiers de l'évêché de Vannes en 1558 (Morice, Preuves, t. III, col. 1224-1225). Roger Doucet souligne par ailleurs que la Bretagne est une des provinces où l'on rencontre le plus de remplaçants envoyés au service (Les Institutions de la France au XVI siècle, t. II, Paris, éditions A. et J. Picard et $\mathrm{c}^{\mathrm{ie}}, 1948$, p. 616).

23. La Noue, François de, Discours..., op. cit., p. 266.

24. Roy, Maurice, Le ban et l'arrière-ban du bailliage de Sens au XVI siècle, Sens, Imprimerie Duchemin, 1885, p. VIII.

25. Arch. dép. d'Ille-et-Vilaine, 2 F 33 (la liasse n'est pas foliotée).

26. Art. XI : " doresnavant, par chascun an, sera faict monstre du ban et arriere ban, et que chascun sera tenu d'y comparoir en personne, en l'estat qu'il est obligé par le debvoir de son fief ". (Bibliothèque nationale, manuscrits français (désormais BnF, fr.), $5503, \mathrm{f}^{\circ} 60$ et suivants). 
vers le milieu du siècle ${ }^{27}$, et l'arquebuse tend à se démocratiser ${ }^{28}$. La jaque de mailles reste une protection bon marché pour les hommes de pied. Ainsi, nous connaissons par le biais de ces montres les revenus nobles des " soldats ", de l'arquebusier au chevalier lourdement équipé.

Les procès-verbaux de l'arrière-ban nous renseignent également sur les hommes qui servent dans une compagnie d'ordonnance. En effet, servir dans l'armée permanente procure l'exemption du service de l'arrière-ban. L'exemption fait tellement d'envieux qu'en 1548, Fourquevaux déplore que l'arrière-ban soit " venu fort bas et le tout procède de ce que chacun veulst estre des ordonnances, pour s'exempter du rière-ban ${ }^{29}[\mathrm{sic}]$ ». Il faut admettre que les compagnies d'ordonnance concentrent un prestige militaire inégalé. Philippe Contamine a ainsi pu dire que le pouvoir royal a échoué à faire de l'arrière-ban " une force militaire solide " en raison du faible prestige que procure l'institution par rapport à l'armée permanente. Servir dans une compagnie d'ordonnance est beaucoup plus prestigieux pour un noble mais du fait du faible nombre de compagnies d'ordonnance en Bretagne, le service de l'arrière-ban reste le cadre principal pour l'expression des valeurs guerrières propres à la noblesse.

De 1541 à 1558, l'arrière-ban est le sujet de nombreuses réformes. L'ordonnance donnée à Blois le 19 mars 1541 introduit trois innovations. Tout d'abord un barème est créé qui définit les classes de revenus et ainsi le service qui correspond au feudataire concerné. Entre 500 et 600 livres de rente, le feudataire devait servir comme homme d'armes à cheval, entre 300 et 400 il devait être chevau-léger ${ }^{30}$. La deuxième innovation est l'apparition d'une infanterie de l'arrière-ban. Les feudataires disposant de 200 à 300 livres devaient servir comme gens de pied ${ }^{31}$. Ainsi, le service était moins onéreux pour la petite noblesse et procurait à la monarchie une

27. Nous disposons de nombreux exemples sur la prédominance du morion et du corselet dès les années 1550. Ainsi, lors d'une montre générale de l'évêché de SaintBrieuc en 1554, le sieur du Cambout, le capitaine des gens de pied de la juridiction de Lamballe, demande à ses soldats de "se tenir prests et en bon equipement selon les dites ordonnances du Roy et auxdits arquebusiers à cheval d'avoir corselets morionds et arquebuses et aux gens de pied d'estre maillés (cotte de mailles) morrionnés et garnis d'arquebuses, hallebardes et picques " (Arch. dép. des Côtes-d'Armor, 1 C 184. Montre du 27 juin 1554).

28. NASSIET, Michel, Noblesse et pauvreté. La petite noblesse en Bretagne, $X V^{e}-X V I I f^{e}$ siècle, Société d'Histoire et d'Archéologie de Bretagne, 1999, p. 134.

29. FourqueVAuX, Instructions sur le faict de la guerre, cité par DoucET, Les Institutions..., op. cit., p. 618. Il s'agit de Raymond de Pavie, baron de Fourquevaux ; il est d'ascendance italienne, mais né à Toulouse. Il fut diplomate et homme de guerre, ainsi que gouverneur de Narbonne.

30. Cavalerie légère. Ces hommes peuvent effectuer des missions de reconnaissance, de garde des flancs lors d'une bataille. Henri IV, conscient de la puissance de ce type de cavalerie, crée une compagnie de chevau-légers au sein de la Maison du roi en 1593.

31. NASSIET Michel, «La noblesse en France...,op. cit., p. 97. François I $^{\mathrm{er}}$ avait déjà essayé d'organiser un service de pied à côté de celui à cheval (Catalogue des actes de François I ${ }^{\text {er }}$, $\mathrm{n}^{\circ} 8490$, acte du 2 juin 1536). 
infanterie non étrangère ${ }^{32}$. En troisième lieu, pour faire face aux difficultés de cette très petite noblesse pour satisfaire aux obligations de l'arrière-ban, ceux dont les revenus étaient inférieurs à 200 livres pouvaient " s'assembler " pour équiper un combattant ${ }^{33}$. Il y eut par la suite plusieurs ordonnances revenant au système précédent. Henri II, par une ordonnance de 1548 , revient au service exclusivement cavalier, et une nouvelle ordonnance en 1554 redéfinit le service uniformément sur le modèle des chevau-légers.

\section{La réforme de 1557 : un service spécifique à la Bretagne}

Mais en Bretagne, certains feudataires continuaient à se présenter à pied aux montres, faute de moyens. En 1555, lors de la tenue des États de Bretagne, suite aux diverses remontrances sur le sujet, le roi demande à une assemblée de statuer sur les problèmes de l'arrière-ban. S'ensuivit le 2 mai 1557 une ordonnance ${ }^{34}$, qui définit, en accord avec la noblesse bretonne, des classes de revenus propres à la Bretagne, avec une pluralité de statuts. L'organisation de l'arrière-ban n'est donc pas uniforme pour tout le royaume $^{35}$; la Bretagne bénéficie ici d'une ordonnance locale qui maintient un régime différent de celui des autres provinces du fait de la situation particulière née de la présence d'une abondante petite noblesse. Le tableau ci-dessous permet de distinguer ces différentes classes de revenus définies par l'ordonnance de 1557.

Un équipement et un armement correspondant aux revenus nobles des feudataires sont attribués selon les classes définies en 1557. Les feudataires sont ensuite organisés en compagnies cohérentes et spécialisées par le type d'armement. On assiste donc à une spécialisation des forces armées. Les feudataires servent dans une compagnie d'hommes d'armes, d'archers, ou encore d'arquebusiers, et se trouvent donc à servir avec des hommes de condition semblable. Cela est d'autant plus visible que les montres les classent de plus en plus par rapport à leur équipement et non plus en fonction de leur paroisse de résidence. Ainsi, on distingue les différentes compagnies de l'archidiaconé de Porhoët en $1569^{36}$ : les hommes d'armes,

32. Suscitant tout de même des réticences de la noblesse qui voit en la cavalerie l'arme noble par excellence.

33. Ainsi, parmi les nombreux cas, " Pierre de la Bousselaye et Jehan du Rocher faisans un Arquebusier " (MoRICE, Preuves, t. III, col. 1224-1225).

34. Morice, Preuves, t. III, col. 1197.

35. À ce sujet, la Normandie bénéfice également d'un statut spécial pour l'arrière-ban. La province disposait d'un capitaine général spécial, et les effectifs étaient aussi regroupés suivant des ordonnances locales particulières (DOUCET Roger, Les Institutions..., op. cit., t. II, p. 616).

36. Monstres generalles des gentilshommes et aultres tenants terres et fieffs nobles ou biens au ban et arrière ban de l'evesche de Saint Malo en l'archidiaconé de Porhoet tenu a Dinan devant nobles gens Jullien du Breuil sieur de pontbriand ", datant du 2 mars 1569. (Arch. dép. d'Ille-et-Vilaine 2 F 7). Publié par SEvEGRAND, Gérard, " Le ban et l'arrièreban de Porhoët au temps des guerres de Religion ", Bulletin et Mémoires de la Société Archéologique d'Ille-et-Vilaine, t. 99, 1996. 


\section{Équipement du ban et arrière-ban de Bretagne, 1557}

(Source : Nassiet Michel, Noblesse et pauvreté..., op. cit., p. 137, tableau 13. Quelques ajouts ont été apportés pour préciser certaines classes de revenus [Morice, Preuves, t. III, col. 1187 et Arch. dép. de Loire-Atlantique, B 121])

\begin{tabular}{|c|c|c|c|}
\hline $\begin{array}{l}\text { Classe de revenu } \\
\text { en livres tournois }\end{array}$ & Fonction et équipement & $\begin{array}{l}\text { Valeur de l'équi- } \\
\text { pement en écus } \\
1 \text { écu = } 47 \text { sols } \\
\text { (ou } 31.11 \text { s.). }\end{array}$ & $\begin{array}{l}\text { Valeur en } \\
\text { livres }\end{array}$ \\
\hline $\begin{array}{l}\text { Supérieur ou égal } \\
\text { à } 1800\end{array}$ & $\begin{array}{l}\text { Homme d'armes accompagné } \\
\text { d'un archer et d'un arquebusier }\end{array}$ & 390 & 897 \\
\hline 1401 à 1800 & $\begin{array}{l}\text { Homme d'armes accompagné } \\
\text { d'un archer }\end{array}$ & 340 & 782 \\
\hline 1001 à 1400 & $\begin{array}{c}\text { Homme d'armes } \\
\text { Dont : - } 2 \text { bons chevaux } \\
\text { - harnois et la lance }\end{array}$ & $\begin{array}{l}250 \\
200 \\
50\end{array}$ & $\begin{array}{l}575 \\
460 \\
115\end{array}$ \\
\hline 801 à 1000 & $\begin{array}{l}\text { Archer accompagné d'un arque- } \\
\text { busier }\end{array}$ & 140 & 322 \\
\hline 501 à 800 & Archer & 90 & 207 \\
\hline 301 à 500 & $\begin{array}{c}\text { Arquebusier à cheval } \\
\text { Dont : - bon courtaut } \\
\text { - arquebuse garnie } \\
- \text { morion } \\
\text { - jacque de maille ou cuirassine }\end{array}$ & $\begin{array}{c}50 \\
30 \\
4 \\
4 \\
12\end{array}$ & $\begin{array}{c}115 \\
69 \\
9,2 \\
9,2 \\
27,2\end{array}$ \\
\hline 201 à 300 & $\begin{array}{c}\text { Homme de pied ou arquebusier } \\
\text { à cheval }\end{array}$ & & \\
\hline 101 à 200 & $\begin{array}{c}\text { Homme de pied } \\
\text { Dont : - corselet } \\
\text { - pique ou hallebarde }\end{array}$ & $\begin{array}{c}16 \\
15 \\
1\end{array}$ & $\begin{array}{c}36,8 \\
34,5 \\
2,3\end{array}$ \\
\hline Jusqu'à 100 & $\begin{array}{c}\text { Homme de pied } \\
\text { Dont : - la pique sèche } \\
\text { - ou l'arquebuse et le morion }\end{array}$ & $\begin{array}{c}1 \\
4 \text { et } 4\end{array}$ & $\begin{array}{c}2,3 \\
18,4\end{array}$ \\
\hline
\end{tabular}

les archers, les arquebusiers à cheval, les " gens à pied aveq le corselet ", et surtout les " arquebusiers archers". Ici on mesure bien l'évolution des armes, les archers ne portent plus l'arc, ce sont des hommes d'armes avec un équipement plus léger (comme pour la gendarmerie), et les " arquebusiers archers " sont en fait des soldats archers comme les précédents, mais armés d'arquebuses ${ }^{37}$. Pour l'évêché de Saint-Brieuc, on observe une

37. Les exemples peuvent ainsi être multipliés, lors des montres générales de l'évêché de Saint-Brieuc, en 1543, les feudataires sont classés par paroisse, et en 1569, ils le sont par équipement militaire : "Les hommes d'armes (26 hommes), archers (40), arquebusiers à cheval (121), gens de pied aux corselets et picques (29), gens de pied avec la picque seiche et l'arquebuse et le morion (163), s'ensuivent les noms de ceux tiennent au desoubz de centz livres rente (320), ensuivent les noms de ceux qui tiennent par acqueste qui doibvent servir d'harquebusier a pied (5), ensuivent les noms de ceux qui se presantent à cause de fiefs nobles qu'ils ont et tiennent (30) ". Arch. dép. des Côtes- 
majorité de gens de pied, les " gens de pied avec la picque seiche et l'arquebuse et le morion " (c'est-à-dire la dernière classe armée, qui possède entre 100 et 150 livres de rentes) ${ }^{38}$. Là encore, le retour à un service de pied pour la Bretagne confirme la proportion élevée de petits nobles dans la province. Mais François de La Noue déplore cette diversité d'armement. Il déclare qu' " on y trouvera des lanciers, des pistoliers, harquebusiers à cheval, simples, et autres armez de cuirasses. On y void encore des arbalestriers à pied, et des hacquebusiers à rouët, et autres armez de cotte de maille avec une javeline rouillee. Les uns se disent gens-d'armes, les autres archers, mais peu sont soldats ${ }^{39}$ ". Le lieutenant général Bouillé est aussi sévère à l'égard de ces combattants. En 1566, il rapporte même son impuissance face à toute menace huguenote : "Je n'auray pas sitost assemblé la noblesse et encores suis-je seurs qu'elle sera si mal montée et en si mauvais equipaige qu'elle ne sera pas en estat de faire grand esfort ${ }^{40}$."

La réforme du système qui paraît indispensable ne fait pas l'unanimité au sein de l'institution. Ainsi, le sieur de Kersimon, capitaine des gentilshommes de l'évêché de Léon déclare en 1557 au duc d'Étampes : « J'ay faict assembler plusieurs des plus imposantz et notables de l'arriere ban de cest evesché pour adviser et deliberer en quel esquipaige ilz se vouldroient et pourroient plus commodement regler pour le service du roy a la defense du pays, et apres avoir longuement conferé dudict faict ont resollu de vous remonstrer incommoditées de cest evesché pour changer leur moyen reglement comme il vous plaira veoyr par le procès verbal que vous envoye, et quelque remonstrance que leur ay faicte ont differé de se reigler autrement que au passé jusques a ce qu'ilz ayent en aultre commandement de vous se confiantz entyerement a vostre acoustumée bonté et bonne volonté qu'il vous a pleu tousjours avoir de les soullaiger ${ }^{41}$ ", ajoutant : " au regard de nostre arriere ban vous congnoissez assez sa force sellon son ancyen reglement, et croy que si vostre bon plaisir seroit de les laisser encores a la mode accoustumée ".

En ce qui concerne les dépenses occasionnées par ce service, l'ordonnance d'Henri II de 1557 définit le service de l'arrière-ban et la valeur des équipements est calculée selon le niveau de revenu, à environ $36 \%$

\footnotetext{
d'Armor C7, 1 (3 juin 1543), f 28 (10 juillet 1569). La dernière catégorie correspond aux roturiers qui possèdent des biens nobles, l'avant dernière correspondrait aux individus qui ont obtenu par acquisition (acqueste), des terres nobles ce qui explique leur faible nombre. Ces derniers sont d'ailleurs tous regroupés sous le même service de pied car leurs biens nobles sont généralement limités mais aussi pour les maintenir dans une dignité inférieure au service cavalier. Je remercie très sincèrement Michel Nassiet pour son aide et ses conseils dans l'interprétation de cette dernière catégorie.

38. Ibid. Ici, il faut entendre que les servants possédaient soit une pique, soit une arquebuse avec dans les deux cas un morion.

39. La Noue, François de, Discours..., op. cit., p. 266-267.

40. Lettre de Bouillé à Catherine de Médicis, Vannes, 21 juin 1566 (BnF, fr. 15542, $\mathrm{f}^{\circ}$ 71).

41. Lettre de Guillaume du Chastel sieur de Kersimon, au duc d'Etampes, 16 juillet 1557 (BnF, fr. 20510, $\mathrm{f}^{\circ}$ 61).
} 
du revenu noble annuel, ce qui en fait une lourde dépense $\mathrm{e}^{42}$. Une arquebuse garnie coûte environ 9,20 livres, ce qui fait le prix de trois vaches ${ }^{43}$. Cependant, même un petit noble pouvait devenir cavalier, comme Michel Nassiet le montre bien avec l'exemple d'une petite famille bretonne qui achète en 1560 trois juments et leur poulain pour 18 livres seulement et se procure trois arbalètes et une lance pour 10 livres $^{44}$. Quant aux feudataires ayant moins de 100 livres de revenus nobles, ils contribuaient à payer la solde mensuelle des capitaines et des officiers du ban et de l'arrière-ban à raison du sol la livre c'est-à-dire $5 \%$ de leurs revenus ${ }^{45}$. Ils sont considérés comme des contribuables et non plus comme des combattants potentiels. Ces feudataires qui disposent de moins de 100 livres de revenus nobles, peuvent être très nombreux. Ainsi, en 1569, pour l'évêché de Saint-Brieuc, ils sont 320 , ce qui représente près de la moitié des feudataires de l'évêché $^{46}$. Seuls vingt-six feudataires ont les moyens de s'équiper en " homme d'armes ${ }^{47}$ ". En fait, la fortune moyenne avoisine la centaine de livres en Bretagne $^{48}$. Ces réformes, qui précèdent de peu les guerres civiles, ont l'avantage de s'adapter aux réalités sociales et militaires des Bretons pour une meilleure effectivité du service.

Cette petite noblesse populeuse assure un service à pied important mais un très grand nombre de feudataires modestes ne peuvent pas même servir au sein de l'arrière-ban. Le nombre important de ces derniers n'est pas compensé par les quelques roturiers mobilisés, d'autant plus que ceux-ci sont limités dans l'acquisition de leurs biens à 500 livres et ne peuvent donc pas servir au-delà de la classe des archers alors qu'ils en auraient les moyens financiers. Finalement, l'ascension sociale permise par la capacité financière de ces roturiers est limitée par le pouvoir royal, soucieux de réserver à la noblesse un des cadres de l'expression de ses valeurs guerrières.

\section{Organisation et logistique militaire}

\section{Fonctionnement et commandement du service}

L'arrière-ban breton est organisé par évêchés. Il y a donc un capitaine de l'arrière-ban pour chaque évêché. Ainsi, en 1562, Tanguy de Rosmadec est le " cappitaine des dicts nobles en l'evesché de Cornouailles ${ }^{49}$ ". Ce

42. NASSIET, Michel, Noblesse et pauvreté..., op. cit., p. 135.

43. NASSIET, Michel, « La noblesse en France..., op. cit., p. 96.

44. Ibid., d'après Arch. dép. du Morbihan, E 627. Toutefois, pour certaines familles, le service de l'arrière-ban restait un service onéreux : un simple morion coûte 9,2 livres !

45. NASSIET, Michel, Noblesse et pauvreté..., op. cit., p. 135.

46. Montre du 10 juillet 1569 ; " s'ensuivent les noms de ceux tiennent au desoubz de centz livres rente" (Arch. dép. des Côtes-d'Armor, C7, f ${ }^{\circ}$ 2).

47. Ibidem.

48. NASSIET, Michel, « La noblesse en France..., op. cit., p. 94.

49. FRÉMINVILLE, «Montre générale de l'Evesché de Cornouailles, faicte à Quimper les $15^{\mathrm{e}}$ et $16^{\mathrm{e}}$ du mois de may 1562 ", Antiquités de la Bretagne : Finistère, Brest, librairie Lefournier et Deperiers, 1852, p. 428. 
capitaine est le plus souvent nommé par le gouverneur. En effet, le duc d'Étampes rappelle bien qu'il a reçu de la monarchie la permission de " pourvoir aux Estats des capitaineries des Bans et Arrière-bans d'icelle " province ${ }^{50}$. Ainsi, c'est le gouverneur Jean de Brosse, duc d'Étampes, qui institue Julien du Breuil comme capitaine de l'arrière-ban de Saint-Malo le 4 avril $1562^{51}$. De plus, pour ce genre de charge, le gouverneur faisait plus facilement confiance à un homme qui commandait déjà une compagnie de l'arrière-ban. Autrement dit, la charge de capitaine de l'arrière-ban est une charge militaire qui est confiée à des hommes d'expérience en la matière. Ainsi, René du Cambout est à la tête d'une compagnie de fantassins, avant de devenir le capitaine de l'ensemble de l'arrière-ban de Saint-Brieuc ${ }^{52}$. Il en va de même pour les commissaires. Avant de devenir commissaire de l'arrière-ban de Saint-Brieuc, le sieur de Souleville ${ }^{53}$ était dès 1559 capitaine d'une compagnie d'arquebusiers à cheval du même évêché ${ }^{54}$.

On distingue les montres en armes des montres "préparatoires ", ou rôles, qui recensent les revenus des feudataires et se tiennent en robe ${ }^{55}$. Les montres sont tenues devant les commissaires de l'arrière-ban (et parfois un commissaire général) députés par le gouverneur. Les déclarations des feudataires sont adressées aux mêmes commissaires, qui sont en général le capitaine du ban de l'évêché et le sénéchal ${ }^{56}$. Les charges de capitaine et commissaire sont assez floues. Le même homme peut assurer les deux fonctions ; plusieurs commissaires peuvent être commissionnés pour une

50. Morice, Preuves, t. III, col. 1216-1217. "Brevet de Capitaine des gentilshommes de l'Evesche de Saint-Malo pour Jean du Guini Sieur de la Garoulaie ", 12 mars 1557.

51. Morice, Preuves, t. III, 1303. "Brevet de capitaine l'arrière-ban de Saint-Malo pour Julien du Breuil, sieur de Pontbrient " du 4 avril 1562. La nomination à ce poste est due au décès de Jean l'Evesque, sieur de Pontharouar, qui laissait donc la charge vacante.

52. Montre du 27 juin 1554. Il est capitaine des " gentilshommes à pied de la juridiction de Lamballe " (Arch. dép. des Côtes-d'Armor, 1 C 184).

53. Il s'agit de Guillaume de Lescouët, sieur de Souleville (parfois écrit Soulleville), pensionnaire du roi en Bretagne, commandant de Quintin depuis le 19 mai 1558 (BnF, fr. 22310, $\mathrm{f}^{\circ}$ 122), capitaine de cinquante arquebusiers à cheval (avril 1559), et commissaire de l'arrière-ban de Saint-Brieuc ; il fut le bras droit armé de Bouillé pour le même évêché.

54. Commission pour M. de Souleville, de capitaine de cinquante gentilshommes harquebusiers à cheval, 11 avril 1559 (BnF, fr. 22310, f ${ }^{\circ}$ 125). Lettre du duc d'Étampes au sieur de Soulleville, du 16 juillet 1562 (Morice, Preuves, t. III, col. 1312-1313. Ibid., col. 1358, pour l'institution en la charge).

55. Un exemple de rôle : "C'est le procès verbal de la monstre des nobles subjects au ban et arrière-ban de l'evesché de Cornouailles, faict en rôle seulement, à QuimperCorentin, les 15e et 16e de may 1562 "(FréMinVILLE, "Montre générale..., op. cit., p. 26).

56. «Bertrand le Voyer, seigneur de Legonniais commissaire desputé par monseigneur le gouverneur de ce pays et duché de Bretaigne pour tenir lesdictes monstres " (Arch. dép. des Côtes-d'Armor, C 7, f 1 : " montres générales de l'Evéche de Saint Brieuc ", 3 juin 1543). "A laquelle monstre a été procédé par nous Charles de Plœuc, sieur de Plœuc, du Timeur, Queuzon, Ergué et commissaire de l'arrière-ban audict Cornouailles. Presant noble et puissant Tanguy de Rosmadec, sieur dudict lieu, Tyvarlen, Mollac, et capitaine des dicts nobles audict evesché de Cornouailles, et pareillement en présence de maistre Georges Lesandevez, Seneschal de Cornouailles, et les lieutenants, advocats et procureurs du Roy audict lieu " (FrÉminVILLE, " Montre générale..., op. cit., p. 428). 
seule montre, il peut s'agir du sénéchal, du capitaine de la place où a lieu la montre, de son lieutenant, d'un juge, ou encore d'un homme élu pour l'occasion ${ }^{57}$. François de La Noue explique cette confusion dans l'encadrement de l'arrière-ban :

" Il a esté dit qu'anciennement les baillifs et seneschaux avoient la charge d'assembler et conduire les arriere-bans. Aujourd'huy c'est encore leur office. Et aux lieux où il n'y en a de robbe courte, on eslit des capitaines, comme on fait en Bretaigne, pour recueillir les hommes, apres que les proclamations sont faites selon les mandemens du roy. Mais pource qu'il n'y a pas grand honneur en telles charges, elles ne sont acceptees ordinairement que par gentils-hommes qui ne bougent du pays, et plus pour la commodité, que pour autre regard. Et combien qu'ils soient honnestes et metables (ayant de la valeur, capables, doués), si est-ce que la pluspart sont sans grande experience des armes, qui fait qu'ils ne prennent pas si pres garde à ceux qui viennent sous eux. Et pour faire plaisir à leurs voisins et amis, ils reçoivent indifferement ce qui se presente ${ }^{58}$."

On comprend bien que le capitaine et le commissaire sont des hommes de la noblesse locale qui fédèrent autour d'eux leurs voisins et amis afin d'obtenir un service effectif. Ce sont le ou les commissaires qui tiennent les registres contenant les revenus nobles des feudataires. En 1578, on apprend par exemple que René de Cambout est capitaine de l'arrière-ban de l'évêché de Saint-Brieuc et que son commissaire est le sieur de Souleville ${ }^{59}$. Mais les deux hommes paraissent sur un pied d'égalité lorsque Georges de Bueil, seigneur de Bouillé, leur écrit pour mobiliser leur arrière-ban face au danger des Malcontents réunis à Alençon en $1578^{60}$. Du moins le commissaire possède-t-il un pouvoir de commandement de l'arrière-ban. Plusieurs fois, sûrement à cause des absences du sieur de Cambout, Bouillé s'adresse à Souleville pour mobiliser les gentilshommes de son ressort ${ }^{61}$. D'ailleurs, Souleville commande désormais l'ensemble des cavaliers de l'évêché ${ }^{62}$. Le pouvoir de l'arrière-ban pouvait ainsi être partagé entre le capitaine et le commissaire général des gentilshommes, mais un homme seul peut également concentrer les deux fonctions en sa personne. Julien du Breuil concentre à lui seul les deux charges et est " capitaine et commissaire général du ban et arrière-ban de Saint-Malo ${ }^{63}$ ". Lors des convocations de

57. Dans les deux montres générales de l'arrière-ban de Saint-Malo tenues à Dinan en 1569, le commissaire pour la première montre est Jean Guiton, sieur de Landesbaron, lieutenant et juge ordinaire de la ville ; et le commissaire pour le seconde est Charles Marot, sieur des Boisbenets, et sénéchal de Dinan.

58. La Noue, François de, Discours..., op. cit., p. 265.

59. Morice, Preuves, t. III, col. 1443-1444.

60. Ibidem. Le roi de Navarre est alors chez François d'Alençon dans son apanage normand, ce dernier reçoit par ailleurs l'Anjou en 1576 à la suite de l'édit de Beaulieu qui consacre le triomphe des Malcontents.

61. Lettres de Bouillé à Souleville de 1568 et 1574 (BnF, fr. 22310, f ${ }^{\circ} 129,133$ et 134).

62. Lettre du duc d'Estampes à Guillaume de Lescouet, seigneur de Souleville, capitaine des harquebusiers à cheval en l'évesché de Saint-Brieuc, 17 juillet 1562 (BnF, fr. 22310, f $\left.{ }^{\circ} 127\right)$.

63. Morice, Preuves, t. III, col. 1303. Brevet de capitaine l'arrière-ban de Saint-Malo pour Julien du Breuil, sieur de Pontbrient, 4 avril 1562. 
1567 et 1568, il est précisé que « Julien du Breil est le premier des commissaires députés pour les monstres des nobles de l'archidiaconné de Dinan, en l'évesché de Saint-Malo, ès années 1567 et $1568^{64}$ ». De plus, il semblerait que certains gouverneurs de places-fortes importantes aient un rôle à jouer dans le commandement de la noblesse en armes. En 1557, lorsque les cinq enseignes de fantassins destinées à combattre en Écosse traversent la Bretagne, les cadres de l'arrière-ban doivent organiser le voyage, les étapes et le stationnement près de Brest. Il apparaît que c'est Marc de Carné, le gouverneur de Brest, qui coordonne l'action et commande aux capitaines et commissaires de l'évêché de Léon ${ }^{65}$. Lorsque le duc d'Étampes adresse des lettres " aux commandans de la noblesse de Bretagne " il les adresse aux capitaines et commissaires des neuf évêchés ainsi qu'aux capitaines des francs-archers, mais également au gouverneur de Brest cité plus haut et à celui de Concarneau (le sieur de Kerroand) ${ }^{66}$.

Le capitaine et les commissaires de l'arrière-ban d'un évêché doivent ensuite répartir les possesseurs de fiefs nobles disponibles de leur ressort en compagnies spécialisées, commandées elles-mêmes par des capitaines de compagnie. En effet, le capitaine et commissaire dispose du " pouvoir de lever compaignies ${ }^{67}$ ". Par exemple, en 1558, Vincent de Kermeno est capitaine de l'arrière-ban de l'évêché de Vannes et doit recruter et entraîner les capitaines de ses compagnies ${ }^{68}$. En 1558, une montre des arquebusiers à cheval de l'évêché de Vannes nous renseigne sur l'origine géographique de ses membres (voir figure 1). On observe clairement un système de proximité des feudataires par rapport à la localisation de la seigneurie du capitaine de leur compagnie, ici Louis de Rieux, seigneur de Coesguel. La majorité des gentilshommes est recrutée dans une aire de moins de $25 \mathrm{~km}$ autour de celle-ci. L'assise territoriale et rurale d'un seigneur influent joue donc dans le recrutement. Les compagnies de feudataires sont désormais des unités fédérées par une origine géographique commune. Dans ce cas précis, l'évêché est divisé en deux parties bien distinctes et on peut supposer l'existence d'une deuxième compagnie d'arquebusiers pour la partie nord-ouest de l'évêché.

64. SAINT-PERn, Revue Historique de l'Ouest, année 12 (1896 - Documents), p. 287-308.

65. Le Sieur de Boishamon, commissaire des gentilshommes de Tréguier, et le Sieur de Coëtnisan, commissaire de ceux de Léon, doivent " conduire lesdites bandes depuis Kerlesquen jusqu'à Landerneau auquel lieu il devoit estre pourveu au reste par les officiers et par les commissaires. Ordonnez par le sieur de Carné ", Lamballe, 6 novembre 1557 (BnF, fr. 22310, f ${ }^{\circ}$ 114). Marc de Carné est gouverneur de Brest et capitaine de l'arrière-ban de Vannes en 1535 (Arch. dép. d'Ille-et-Vilaine, 2 Ec 8, Carné 4, Titres de la famille Carné, $\mathrm{f}^{\circ}$ 76). Marc de Carné est également le commissaire des évêchés de Vannes, Nantes et Rennes en 1543 (Ibid., $\mathrm{f}^{\circ} 78 \mathrm{v}^{\circ}$ ).

66. BnF, fr. $22310, \mathrm{f}^{\circ} 145$.

67. Morice, Preuves, t. III, col. 1356.

68. Morice, Preuves, t. III, col. 1231 (il est écrit de Kerveno mais il faut croire que c'est de Kermeno puisqu'à la colonne 1224, il en est fait mention pour la même charge avec cette orthographe-ci). Ou encore, le capitaine Souleville en 1568 reçoit la charge de capitaine de l'arrière-ban de Saint-Brieuc après le sieur de Rouvre, col. 1358. 


\section{Figure 1 - Origine géographique de 50 arquebusiers de l'évêché de Vannes}

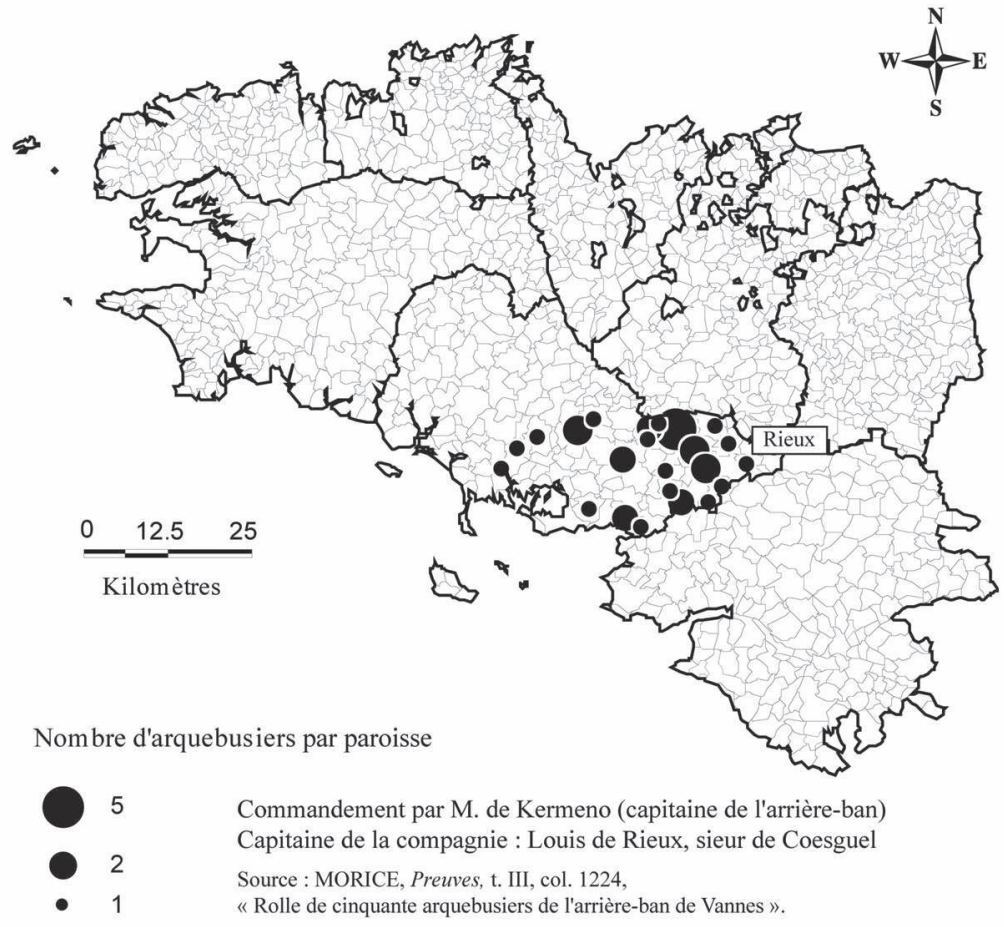

Réalisation : Antoine Rivault

Mais au début des troubles, la situation n'est pas aussi claire que par la suite. Plusieurs unités ne forment pas encore des " compagnies " à proprement parler. Certains capitaines disposent d'un nombre défini de servants et organisent alors des compagnies le temps d'une mission. Par exemple, on peut lire lors d'une montre des gentilshommes de l'évêché de Cornouaille en 1562 :

"Et resuivant les dicts lettres escriptes au dict sieur de Tyarlen, leur capitaine, ont esté enrôlés vingt gentilhommes du dict arrière-ban, auxquels il est commandé de se trouver en leur garnison au chasteau de Concq à jeudy prochain, sous la charge du sieur de la Porte-Neuve, présent, et ont juré luy obéir comme le chef. Aussi suivant les lettres de monseigneur le gouverneur ont esté présentement choisis et levés par le dict seigneur de Tyvarlen tant des hommes d'armes, d'archers et d'arquebusiers à cheval, leur est ordonné de se trouver à Pontivy au vingt septième de may présent mois, avec le dict sieur de Tyvarlen pour le service du Roy. Lesquels rôles ont esté leûs publiquement en ladicte assemblée, bannies faictes, et sommé en tel cas à s'y y trouver ${ }^{69}$."

69. FRÉMINVILLE, « Montre générale..., op. cit., p. 479. 
Figure 2 - Origine géographique des feudataires de l'arrière-ban de Cornouaille en 1562

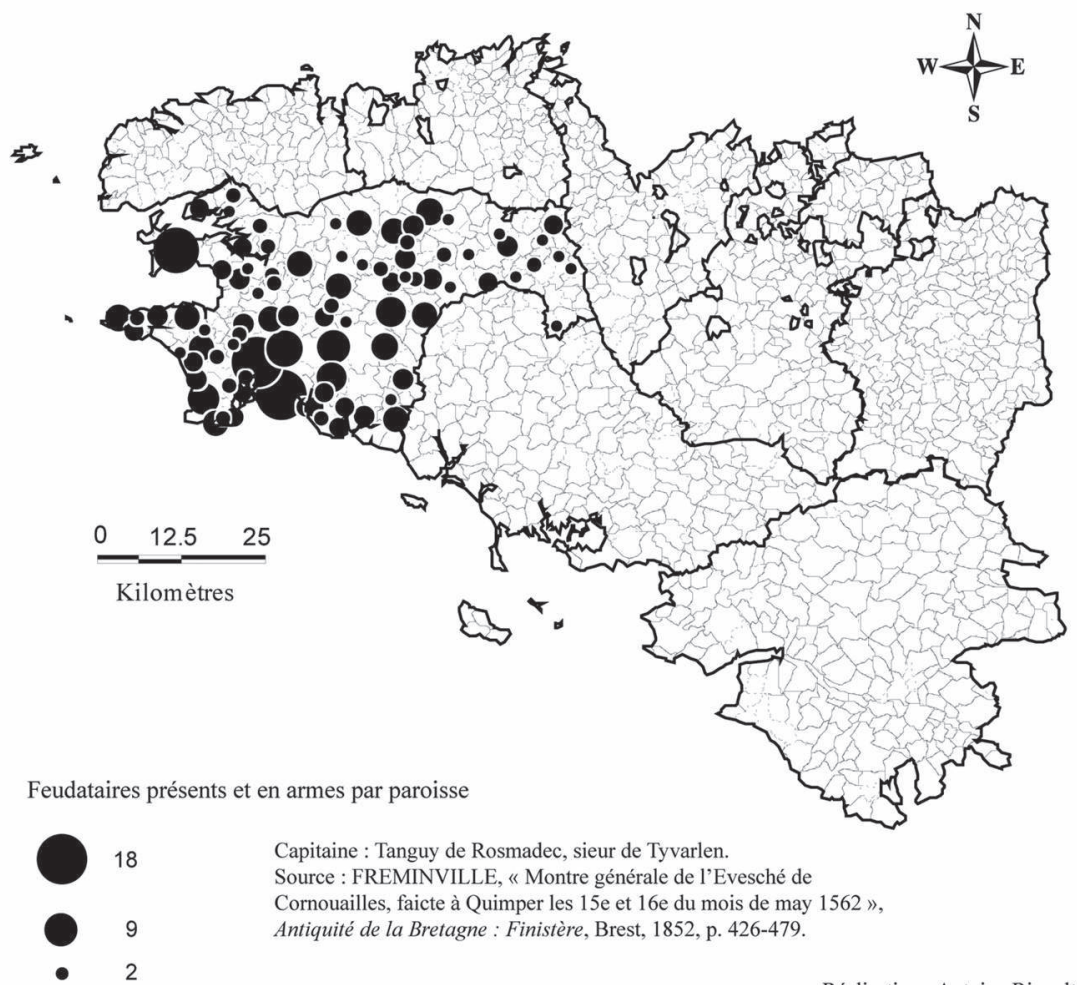

Réalisation : Antoine Rivault

Aucune compagnie n'est clairement formée pour cet évêché (voir carte ci-dessus), la situation diffère vraiment selon l'évêché et l'encadrement local. On aperçoit bien la différence entre l'évêché de Cornouaille et celui de Vannes, l'un gère des feudataires à l'échelle de l'évêché, l'autre des compagnies déjà spécialisées. La tendance va vers cette dernière gestion en s'accompagnant alors d'une mutation des montres. On ne recense plus les feudataires en fonction de leur paroisse mais de plus en plus en fonction de leur compétence militaire. Au début des années 1560, certaines montres continuent de recenser les gentilshommes par paroisse mais dès les années 1570 on ne trouve plus que des compagnies spécialisées.

Certains capitaines peuvent également diriger personnellement une compagnie de feudataires. En 1574, Christophe de Poix, seigneur de Fouesnel, est capitaine de l'arrière-ban de l'évêché de Rennes et est aussi " cappitaine " d'une compagnie de 30 soldats de l'arrière-ban ${ }^{70}$. On l'a vu,

70. SAulnier, Frédéric, "La maison de Poix et la seigneurie de Fouesnel en Bretagne d'après des documents inédits ", Mémoires de la Société d'Archéologie d'Ille-et-Vilaine, tome xv, 1881, p. 282-283 ("Rôle de la compagnie de Christophe de Poix "). 
souvent, les capitaines diocésains du ban commandaient déjà une compagnie avant leur nomination et la charge a pu rester entre leurs mains lors de leur promotion. Lorsqu'il passe en revue l'arrière-ban de son ressort, le capitaine et commissaire peut procéder par division géographique. Ainsi, Julien du Breuil effectue une montre générale des gentilshommes en l'évêché de Saint-Malo, tenue à Dinan du 2 au 7 mars $1569^{71}$. Les deux montres des archidiaconés nous renseignent sur le fait que ces hommes sont répartis selon leur armement (et non plus la paroisse de résidence). Ainsi, l'archidiaconé de Porhoët dénombre 13 hommes d'armes, 14 archers, 62 arquebusiers à cheval, 53 arquebusiers archers, et 15 hommes de pied ; celui de Dinan : 6 hommes d'armes et 6 archers qui doivent se tenir à Nantes, 39 arquebusiers à cheval (capitaine La Varaine), 42 hommes de pied (capitaine Boisfeillet) qui tiennent garnison à Lohéac.

\section{L'arrière-ban : un vivier de recrutement pour l'armée royale}

Il ne faut pas oublier qu'il existe des liens forts entre la gendarmerie et l'arrière-ban. En effet, il existe des hommes capables de s'armer en gendarmes qui servent dans l'institution féodale mais ceux-ci sont très peu nombreux car ils viennent le plus souvent alimenter les rangs des ordonnances. En fait, il s'agit des meilleurs éléments de la noblesse en armes. François de La Noue, dans sa célèbre diatribe sur la noblesse et son service militaire, soutient que la monarchie a puisé ses réserves de gendarmes au sein de l'arrière-ban, et que ce dernier, privé de ses meilleurs éléments, est alors tombé en décadence. Pourtant, il rappelle bien que " la difference qu'il y a entre les uns et les autres, n'est pas aux hommes. Car la mesme noblesse qui au temps passé servoit d'une façon, sert à ceste heure d'une autre. La diversité est en la militie [le service en armes] qui a esté changee ${ }^{72}$ ". Mais certains nobles pouvaient toujours espérer intégrer les ordonnances sans disposer d'un revenu mirobolant. Ainsi, Jehan Aguillon déclare 97 livres de revenu noble à la montre de l'arrière-ban de Rennes en $1541^{73}$. Proche de François du Gué (les terres des deux hommes sont voisines), enseigne de la compagnie du duc d'Étampes et qui est gouverneur de Rennes, celui-ci « auroit naguere promys audict exposant de le recevoir soubz sa charge, au moien de quoy

71. Monstres generalles des gentilshommes et aultres tenants terres et fieffs nobles ou biens au ban et arrière ban de l'evesche de Saint Malo en l'archidiaconé de Porhoet tenu a Dinan devant nobles gens Jullien du Breuil sieur de Pontbriand, du 2 mars 1569 (Arch. dép. d'Ille-et-Vilaine, 2 F 7 ; " Ban et arriere-ban de l'Evesché de Saint-Malo en l'archidiaconé de Dinan ", 7 mars 1569 (Morice, Preuves, t. III, col. 1359). Cela correspond aux deux archidiaconés de l'évêché de Saint-Malo, Porhoët au sud et Dinan au nord.

72. La Noue, François de, Discours..., op. cit., p. 260.

73. SĖVEGRAND, Gérard, "La montre des gentilshommes de l'évêché de Rennes, de 1541 ", Bulletin et Mémoires de la Société Archéologique d'Ille-et-Vilaine, 1994, tome XcVI, Rennes, p. 111-169. Il rend aveu au roi pour sa terre de la Bréhonnière-en-Piré en 1540 (Arch. dép. de Loire-Atlantique, B 2149), cité dans Les lettres de pardon du voyage de Charles IX (15651566), NASSIET, Michel (éd.), Genève-Paris, Droz-Société de l'histoire de France, 2010, p. 28. 
icelluy suppliant, adverty que ladicte compaignie devoit faire monstre en nostre ville de Nantes, y seroit allé avec deux pistolles dans ses chausses, chargées, bandées et emorchées ${ }^{74}$ ". Cet exemple montre que ce ne sont pas inexorablement les plus fortunés et les mieux armés qui servent au sein des ordonnances. Aguillon a moins de 100 livres de rente et possède pour seul et unique armement deux " pistolles ". Mais il s'agit là du cas unique et isolé d'un individu qui espère s'élever socialement par le métier des armes, tout en quittant le lourd service de l'arrière-ban, en faisant jouer ses relations (François du Gué fait également fonctionner sa clientèle). Aguillon a ainsi pu servir au sein d'une compagnie de feudataires que commandait François du Gué (capitaine de l'arrière-ban de Rennes), avant de rejoindre sa compagnie de gendarmes. Il en va de même pour Vincent de Bintinaye " qui estoit au service du roy sous la charge et suitte du Gouverneur de Rennes [...] du nombre des cent arquebuziers à cheval dont le sieur du Gué étoit capitaine ${ }^{75}$ ". Des membres d'une même famille pouvaient espérer une certaine ascension sociale en passant de l'arrière-ban à la gendarmerie. Ainsi, Raoul Pigeault, sieur de la Mélatière, est employé dans l'arrière-ban de Saint-Malo de 1543 à 1569, et son fils, Samuel, est gendarme de la compagnie du vidame de Chartres à la prise de Calais en $1558^{76}$.

Ceux qui restent donc au sein du service banal proviennent d'une catégorie sociale s'apparentant à la moyenne noblesse locale. Ils n'ont pas (encore) les moyens d'entrer dans la gendarmerie mais se retrouvent être les meilleurs éléments nobles du service féodal. C'est sur eux que le gouverneur peut s'appuyer en cas de danger. François de La Noue prend l'exemple de la Bretagne pour mettre en évidence cette noblesse capable à ses yeux du meilleur maintien de l'ordre provincial possible ${ }^{77}$. Nous apprenons alors que "de la Bretagne on tireroit trois cens bons chevaux, qui equipolent à trois compagnies de gendarmes ${ }^{78}$ ". Nous savons que la moyenne des gendarmes servant dans le service banal est d'environ $30 \mathrm{ou}$ 40 gentilshommes par évêché ; en comptant les 9 évêchés de la province, on s'aperçoit que La Noue fait référence à ces meilleurs éléments de l'arrière-ban. Il mise ainsi sur l'efficacité de certains plutôt que sur le nombre, en préférant " vingt et cinq bons hommes, que cent equippez comme il a esté dit, qui ne servent ordinairement que d'effrayer les païsans et devo-

74. Lettre de pardon donnée à Toulouse, en février 1565 (Les lettres de pardon..., op. cit., NASSIET, Michel (éd.), p. 28).

75. 15 mars 1567 et 5 janvier 1569 (Revue Historique de l'Ouest, année 13, 1897, p. 355-364).

76. Potier De Courcy, Pol, Nobiliaire et armorial de Bretagne, 1890, t. II, p. 387. Il s'installe durablement à Calais et s'y marie en 1573 à Jeanne Hamilton (sûrement d'origine anglaise); sa branche produisit trois mayeurs de Calais.

77. La Noue, François de, Discours..., op. cit., p. 258. La Noue croit sincèrement dans les capacités de ce service : "Ces vieilles reliques de noblesse qu'on laisse trainer en la poudre, si elles estoient un peu r'agencees par bon ordre, apporteroient du fruict, et a l'avanture plus qu'on ne pense."

78. Ibid., p. 271. 
rer leurs victuailles ${ }^{79}$ ". Il préconise ainsi pour ces troupes de s'équiper sur le modèle du reître avec des " corselets noirs assez légers, car les pesans accablent, avec les cuissots, demy brassals, et la bourguignotte, puis une bonne et longue pistole, avec le cartouche plein de charges, et ne porteroyent nulles casaques pource que le vray reitre ne doit faire paroistre que fer et feu ${ }^{80} "$.

Au niveau des hautes carrières militaires, le capitaine et commissaire peut également faire partie du commandement de l'armée royale. Ainsi, Julien du Breuil, seigneur de Pontbriand, est capitaine d'une compagnie de 300 hommes de pied de l'infanterie du roi, et capitaine et commissaire général de l'arrière-ban, des élus et des francs archers de l'évêché de Saint-Malo depuis $1562^{81}$. Il se sert d'ailleurs sûrement de cette dernière charge pour recruter ses hommes parmi l'arrière-ban et les francs-archers. Cumuler la charge de capitaine de l'arrière-ban avec le commandement d'une unité de l'armée royale pouvait également apparaître comme une légitimité de plus pour l'intéressé. En 1562, Julien du Breuil et tant d'autres capitaines bretons de l'arrière-ban ont par ailleurs été appelés par le duc d'Étampes pour former son armée lors de la pacification de la Basse-Normandie puis du siège de Rouen ${ }^{82}$.

\section{L'arrêt des montres générales : vers une spécialisation des compétences militaires}

Il est difficile de distinguer les levées générales de l'arrière-ban ${ }^{83}$, qui s'appliquent à tout le royaume, des levées locales, limitées à l'étendue d'une province ${ }^{84}$. Lorsque le roi voulait convoquer l'arrière-ban, il le faisait par lettres patentes destinées aux baillis et sénéchaux, dans lesquelles il fixait le jour de la convocation. L'arrière-ban breton fut convoqué à plusieurs reprises lors des guerres de Religion. Dès le début des troubles, en 1562, Charles IX convoque l'arrière-ban de Bretagne ${ }^{85}$, puis, lors de la seconde

79. Ibid., p. 273.

80. Ibid.

81. Par lettres patentes du 4 avril 1562. Rosmorduc, Georges de, La Noblesse de Bretagne devant la Chambre de réformation, Saint-Brieuc, 1905, tome III, p. 146 ; MoRICE, Preuves, t. III, col. 1303, 1307, 1359. C'est son oncle, Roland du Breuil, qui devient le guidon des gentilshommes de Saint-Malo en 1573 (SAINT-PERN, "Breuil (du) ", Revue Historique de l'Ouest, année 12 (1896 - Documents), p. 230-231. Mandement du 15 février 1573).

82. BnF, fr. $15876, f^{\circ} 275$. Lettres du duc d'Étampes à la noblesse de Bretagne, Nantes, 21 juillet 1562.

83. Il y aurait eu 4 convocations générales sous Louis XII, 5 sous François I $^{\text {r }}, 7$ sous Henri II, 4 sous Charles IX, 2 sous Henri III et aucune sous Henri IV (LEBEURIER, Rôle des taxes de l'arrière-ban du baillage d'Évreux en 1562, Paris, Dumoulin, 167 p.).

84. Par exemple, sous François I ${ }^{\text {er }}$, les levées de 1534, 1536, 1537, 1538, et 1545 sont générales mais l'incertitude règne quant à celles de 1525 et 1543 (DOUCET Roger, Les Institutions..., op. cit., p. 617).

85. FREMINVILLE, « Montre générale..., op. cit., p. 426. 
et de la troisième guerre, à nouveau en 1567 et en $1568-1569^{86}$. Lors des problèmes occasionnés par les Malcontents, et notamment à Vitré, les gentilshommes bretons sont convoqués en 1574-1575 ${ }^{87}$. Mais il est également nécessaire de distinguer les levées générales d'une province, des levées encore plus locales, qui s'effectuent le plus souvent à l'échelle du diocèse. Le gouverneur pouvait ainsi faire appel - selon ses inquiétudes - à un seul diocèse, voire à une seule compagnie de celui-ci, sans pour autant mobiliser l'arrière-ban entier de la province. En effet, trois échelles se superposent, celle de la province, celle du diocèse et enfin, celle de la simple compagnie. Ainsi, en Bretagne, après 1570, le pouvoir royal semble renoncer à convoquer des montres générales et mobilise les gentilshommes fidèles et compétents avec des montres locales ${ }^{88}$. Comment expliquer ce tournant dans la convocation des feudataires?

Il apparaît qu'avec le caractère sporadique des guerres de Religion et les inquiétudes répétées, le pouvoir royal adapte le service de l'arrièreban face aux menaces qui sont souvent de faible envergure et se sert de l'arrière-ban ponctuellement pour remédier à son manque de troupes, sans pour autant mobiliser entièrement celui-ci. En effet, nous avons vu qu'une convocation mobilise les feudataires pour les trois mois à venir, ce qui laisse neuf mois de l'année sans service possible. Le gouverneur et ses lieutenants préfèrent donc jouer sur les rotations des compagnies, plutôt que d'épuiser le potentiel militaire de l'arrière-ban en le convoquant d'un seul coup. Il devient davantage une force de maintien de l'ordre et de défense de la province plutôt qu'une force militaire offensive.

Il ne faut pas oublier que les feudataires sont organisés en compagnies distinctes depuis que le règlement de 1557 a créé des catégories sociales distinctes. Dès 1559, le duc d'Étampes demande au capitaine Souleville d'organiser une compagnie de feudataires et de "mectre sus en ledit pais le nombre de cinquante harquebuziers à cheval pour estre prests à faire monstre ${ }^{89}$ ". Dès le début des troubles, le duc d'Étampes " crains de mectre les armes au poing a plus qu'il n'en seroit besoing, ne les ayant encores faict prendre que a quelque petit nombre d'entr'eulx que j'ay faict choaisir des plus certains ${ }^{90}$ ». Par ces mots, le gouverneur résume bien toute l'ambiguïté

86. " ayant mandé et assemblé ce qu'il auroit peu promptement des ban et arriere ban " (Arch. dép. des Côtes-d'Armor, 1 C 184 et Arch. dép. de Loire-Atlantique, B 56, f ${ }^{\circ} 222$ v $^{\circ}$ ). 87. Arch. dép. de Loire-Atlantique, 2 E 556.

88. Dernières montres générales par évêché : 1567 : Rennes (BnF, fr. 22310, f 207 . Tenüe des monstres générales du ban et arrière-ban de l'évesché de Rennes, du 15 novembre 1567). 1569 : Saint-Malo (Arch. dép. d'Ille-et-Vilaine 2 F 7 (archidiaconé de Porhoët). Dinan (Morice, Preuves, t. III, col. 1360). 1569 : Saint-Brieuc (Arch. dép. des Côtes-d'Armor, 1 C 184). 1570 : Tréguier (Arch. dép. des Côtes-d’Armor, 1 C 184). Pourtant, un ordre de Bouillé à Julien du Breuil en 1573 lui ordonne de " faire la monstre du ban et arrière ban de Bretagne " (SAINT-PERn, Revue Historique de l'Ouest, année 12 (1896 - Documents), p. 225262, 28 avril 1573). Il faut croire que la montre générale n'eut pas lieu.

89. Commission du duc d'Étampes à Souleville, 11 avril 1559 (BnF, fr. 22310, f $\left.{ }^{\circ} 124\right)$.

90. Lettre du duc d'Étampes à Charles IX, Nantes, 16 mai 1562 (LuBLINSKAYA, Aleksandra, Documents..., op. cit., p. 55). 
de la guerre civile, il doit armer les feudataires pour garantir le maintien de l'ordre mais n'a pas besoin de tous et se méfie de certains qui pourraient être gagnés par la cause réformée.

Parfois, il est simplement inutile de mobiliser l'ensemble des feudataires pour une mission qui ne demande qu'un faible nombre de soldats. C'est le cas pour la défense de places fortes. En 1554, l'ensemble de l'arrière-ban de Rennes ne formait qu'une seule et unique compagnie de gentilshommes, qui tenait garnison à Carhaix ${ }^{91}$. En 1558, c'était tout l'arrièreban de Rennes qui était mobilisé pour tenir garnison à Nantes ${ }^{92}$. Face à la montée des troubles, il apparaît que des convocations plus régulières de l'arrière-ban furent inévitables. Le duc d'Étampes rapporte même que vu " le peu de secours que j'ay trouvé de la gendarmerye [...], me retrouvant desgarniz il m'est necessaire de recourir aux gentilz hommes, lesquelz je y ay desja si souvent emploiez qu'ilz ne veullent plus continuer sans les deffraier qui n'est pas (comme vous pourrez penser madame) a petite despence $^{93}$ ". Dès 1562 , les capitaines du ban changent de stratégie. La défense d'une place forte comme celle de Dinan ne nécessitait pas la mobilisation de l'ensemble de l'arrière-ban de Saint-Malo. Ainsi, le sieur de Rieux, lieutenant de Dinan, organise la garnison en divisant l'arrièreban en trois compagnies, qui se relaient " pour servir chacun tiers dix jours ${ }^{94} "$. Une décennie plus tard, en 1573, en pleine guerre contre les Rochelais et les Anglais qui ont pris Belle-Île, Bouillé écrit à son oncle Talvern en lui disant que si besoin est, il peut mobiliser en garnison, pour la sécurité de Saint-Malo, la seule enseigne de gentilshommes du sieur de la Cosnelaye ${ }^{95}$. Celui-ci est d'ailleurs décrit comme un homme de confiance et efficace en ces termes : "en qui je me fie beaucoup pour ce que je le connois fort homme de bien et bien homme de guerre ". Suite aux troubles de la surprise de Vitré par les Malcontents en février 1574, c'est seulement une compagnie de 30 soldats de l'arrière-ban de Rennes qui est mise en garnison dans la ville dès le mois de mars sans pour autant mobiliser tout l'arrière-ban de l'évêché de Rennes ${ }^{96}$. De la même manière, pour la défense de la place forte de Fougères en 1577, Bouillé ne mobilise que les gentilshommes de l'évêché de Rennes qui sont arquebu-

91. " Michel de Poys, sieur de Fouesnel, capitaine, Mathurin Guédouyn, sieur de la Dobyais, enseigne, Georges le Bel, sieur de la Tour, guydon, Jullian Gillet, sieur de Noyal, maréchal des logeix " (SAULNIER, Frédéric, "La maison de Poix..., op. cit., p. 280).

92. "Arrière-ban de Rennes, convoqué à Nantes par le duc d'Estampes ", en 1558 (BnF, fr. $\left.22310, \mathrm{f}^{\circ} 143-144\right)$.

93. Lettre du duc d'Étampes à Catherine de Médicis, Rennes, 17 novembre 1561 (BnF, fr. $\left.15875, \mathrm{f}^{\circ} 395\right)$.

94. Arrière-ban de Saint-Malo en juin 1562 (Bibl. mun. de Rouen, ms. Martainville 200-4, $\left.\mathrm{f}^{\circ} 1\right)$.

95. LA BORDERIE, Arthur de, "Armements maritimes des malouins au XVI siècle ", Bulletin et Mémoires de la Société Archéologique d'Ille-et-Vilaine, IV, 1866, p. 299, 301.

96. Rôle de la compagnie de Christophe de Poix (SAULNIER, Frédéric, " La maison de Poix..., op. cit., p. 282-283). 
siers $^{97}$. Selon ses besoins et le type de missions qui l'occupe, le pouvoir royal mobilise donc certains gentilshommes. Il est inutile de mobiliser des cavaliers pour la défense d'une place forte. D'autres fois, le gouverneur ou ses lieutenants, face à une dangereuse menace, ne désirent convoquer que leurs meilleurs éléments. En 1574, les chevau-légers de l'évêché de Saint-Brieuc sont assignés à la garde des côtes, tandis que les gens de pied sont demandés sur les marches de Bretagne, aux alentours de SaintMalo $^{98}$. En 1578 c'est l'inverse, lorsque Henri de Navarre rassemble ses forces à Alençon après s'être évadé de la cour, le comte de Montgomery étant à Ducé ${ }^{99}$, Bouillé écrit aux sieurs de Cambout et de Souleville, respectivement capitaine et commissaire de l'arrière-ban de Saint-Brieuc, et leur demande de lui envoyer les meilleurs et les mieux équipés des gentilshommes de l'évêché ; [pendant que] " les pauvres qui ne sont bien équipés, laissez-en jusqu'à environ la moitié ou le tiers pour la garde des costes, et qu'ils se tiennent la en armes ${ }^{100}$ ".

Finalement, avec l'arrêt des montres générales, on observe une affirmation des spécialisations et des compétences militaires. Le gouverneur ne convoque plus l'ensemble des feudataires mais la ou les compagnies correspondant(es) aux missions requises. L'ordonnance de 1557 incite à agir dans ce sens. Le pouvoir royal a mis en place un réseau de compagnies spécialisées, il n'a plus qu'à s'en servir en conséquence. La charge de capitaine d'une compagnie spécialisée au sein de l'arrière-ban devient pour le lieutenant général Bouillé un élément d'importance pour s'assurer des fidélités nobiliaires. Ainsi, au tournant de l'abandon des montres générales, celui-ci s'applique à donner "l'état et charge de Capitaine des arquebusiers a cheval de l'arrière ban de l'evesché de Vannes " à Gilles du Bahuno en $1569^{101}$. Une partie de l'arrière-ban est également renforcée dans son caractère militaire, les meilleurs éléments sur lesquels peut compter le pouvoir royal, sont privilégiés lors des graves menaces. Une autre partie des feudataires est renforcée dans son rôle de défense de la province, que ce soit pour la défense du littoral ou celle des places fortes des marches de la province pour les évêchés de Haute Bretagne.

97. "Tous les arquebusiers de l'Arriere-ban de cet Evesché vont à Fougères [...] avecques Monsieur de la Roberie Capitaine des gentilshommes de ladite Evesché ", du 26 février 1577 (MoricE, Preuves, t. III, col. 1433).

98. BnF, fr. $22310, \mathrm{f}^{\circ} 134 \mathrm{r}^{\circ}$

99. Ducey, aujourd'hui à $5 \mathrm{~km}$ au sud du Mont-Saint-Michel.

100. "À cette cause ne faillez de m'envoyer les Gentilshommes de vostre Evesché, et qui sont en meilleur équipement et qui ont moyen de l'estre. Pour les pauvres qui ne sont bien équipés, laissez-en jusqu'à environ la moitié ou le tiers pour la garde des costes, et qu'ils se tiennent la en armes " (Morice, Preuves, t. III, col., 1443-1444).

101. Preuves de noblesse pour la Grande Écurie du Roy, Nantes, 23 mai 1569 (BnF, fr. $\left.32071, \mathrm{n}^{\circ} 4, \mathrm{f}^{\circ} 14 \mathrm{v}^{\circ}\right)$. 


\section{Un service encore effectif?}

L'union du duché au royaume de France, opérée par les mariages successifs de la duchesse Anne avec Charles VIII et Louis XII puis par l'édit d'Union de 1532, entraîna de facto la Bretagne dans les guerres menées par la France. Ainsi, l'arrière-ban breton fut convoqué plusieurs fois au cours du XVI ${ }^{\mathrm{e}}$ siècle, à l'occasion des descentes anglaises de 1512, 1513 et 1522, puis de la descente espagnole à Belle-Île en 1528. En effet, les feudataires de l'évêché de Saint-Brieuc sont convoqués en 1523 à Carhaix, ceux de Rennes en 1528 pour s'opposer aux Espagnols descendus à Belle-Île ${ }^{102}$. Dès le début des années 1550 , les gentilshommes de la province servent pour des missions de garnison et de défense des côtes face aux Anglais et aux Espagnols ${ }^{103}$. Le service féodal apparaît comme la principale force armée de la province, car celle-ci ne dispose que de très peu d'unités de gendarmerie. En effet, en 1561, le vicomte de Martigues rassemble les gentilshommes en armes " puisque nous n'avons icy autres forces ${ }^{104}$ ". Mais avec les débuts des troubles religieux, l'ennemi est autant intérieur qu'extérieur. L'institution doit donc également assurer le maintien de l'ordre quotidien. Sauf que la réforme protestante touche la noblesse en armes et le service féodal en pâtit en conséquence.

\section{Un service encore vivace et cohérent}

"Le roy tiendra le plat-pays en seureté par le moyen des gouverneurs, baillifs, seneschaux et de la noblesse, et, quand sera besoin, vous aidera de leurs forces ${ }^{105}$."

Ces mots de Michel de l'Hospital illustrent bien le fait que la noblesse en armes reste encore une force de maintien de l'ordre du plat-pays. La noblesse rurale apparait alors comme un outil efficace pour la monarchie et ses agents (comme le gouverneur, les lieutenants généraux, et les sénéchaux) pour faire régner l'ordre localement dans la province. En effet, la cohésion sociale des feudataires au travers de la compagnie dans laquelle ils servent reste de mise toute l'année, au-delà du temps trimestriel d'une convocation. Les uns et les autres se connaissent, résident le plus souvent à proximité et savent avec qui ils doivent combattre en cas d'alarme ou d'émotion populaire.

102. NASSIET, Noblesse et pauvreté..., op. cit., p. 134 : convocations des montres en 1513 , 1523, 1528 (Arch. dép. de Loire Atlantique, B 21, f 107 ; Morice, Preuves, t. III, col. 958 ; PARFOURU Paul, "Anciens livres de raison de familles bretonnes conservées aux Archives d'Ille-et-Vilaine ", Bulletin archéologique de l'Association bretonne, 1897, t. XVI, p. 413).

103. NASSIET, Michel, Ibid, p. 135. 1543 : gentilshommes de l'évêché de Saint-Malo à Lesneven en Basse-Bretagne. 1553: 19 nobles de l'arrière-ban de l'évêché de Saint-Brieuc gardent le château de la Roche-Gouyon près du Cap-Fréhel. Novembre 1555 : à Dinan, montre " des gentilshommes " sûrement de l'évêché de Saint-Malo (MoRICE, Preuves, t. III, col. 1030, 1097, et 1147). Également à Nantes en 1543, à Quiberon en 1552 (BnF, fr. 22310, f 9), Belle-Île en 1553. 104. Lettre de Martigues à Catherine de Médicis, Nantes, 24 mai 1561 (BnF, fr. 15875, $\left.f^{\circ} 507\right)$.

105. L'Hospital, Michel de, Discours pour la majorité de Charles IX, présenté par Robert Descimon, Imprimerie Nationale, 1993, p. 88. 
Dès 1543, puis en 1552-1553-1554, les gentilshommes de la province servent pour des missions de garnison et de défense des côtes face aux Anglais et aux Espagnols. En 1543, des gentilshommes de l'évêché de SaintMalo tiennent garnison à Lesneven en Basse-Bretagne ${ }^{106}$. Ainsi, lorsqu'une menace de descente anglaise pèse sur les populations de la baie du Morbihan, dès 1552, le seigneur de Rosmadec rassemble ses gentilshommes pour aller tenir garnison à Quiberon ${ }^{107}$. Dans le même contexte, en 1553, une grande partie de la noblesse en armes se mobilise pour tenir garnison à Belle-Île, puis sur l'île de Rhuys. La carte ci-après illustre bien le fait que tout l'évêché se mobilise pour cette mise en défense. Certes, la mobilisation est essentiellement littorale mais certaines paroisses terriennes ne sont pas en reste et mobilisent un nombre important de feudataires.

La même année, 19 nobles de l'évêché de Saint-Brieuc gardent le château de la Roche-Gouyon près du Cap-Fréhel ${ }^{108}$. En 1554, des garnisons se tiennent à Vannes, l'île de Rhuys et Auray ${ }^{109}$. Cette dernière ville accueille probablement les mêmes nobles de Cornouaille qui ont défendu Quiberon en $1552^{110}$. En 1554, François de Rohan, seigneur de Gyé, lieutenant général du roi en Bretagne, ordonne « la conduite des gentilshommes et nobles personnes du ban et arrière-ban de ceste evesché de Rennes, de ceste ville de Rennes jusques au lieu et ville de Khays (Carhaix), garnison désignée ". Les habitants doivent fournir "vivres pour eulx et leurs chevaulx ${ }^{111}$ ". Cette opération mobilise ainsi la noblesse rennaise à la défense de l'arrière-pays breton. En novembre 1555, une montre " des gentilshommes ", sûrement ceux de l'évêché de Saint-Malo, tiennent garnison à Dinan ${ }^{112}$. En octobre 1557, des gentilshommes arquebusiers à cheval de l'évêché de Saint-Malo sont placés en garnison à Saint-Suliac et Pleudihen pour protéger l'estuaire de la Rance de toute tentative de descente ennemie anglaise ou espagnole ${ }^{113}$. Le 24 août 1557, est rédigé un " rolle des nobles subjectz aux bans et aryere ban de lesveche de Leon esleuz a tenir garnison en la ville de Saint-Renan ${ }^{114}$ ". La montre présente 33 hommes d'armes et 281 archers. Ils participent sûrement ensuite aux combats qui ont lieu

106. NASSIET, Michel, Noblesse et pauvreté... op. cit., p. 135. Également à Nantes en 1543.

107. Rolle du seigneur de Rosmadec des gentilzhommes nommez pour aller tenir garnison à Quiberon, 9 juillet 1552 (BnF, fr. 22310, f $^{\circ}$ 9).

108. NASSIET, Michel, Noblesse et pauvret..., op. cit., p. 135.

109. NASSIET, Michel, "La noblesse en France..., op. cit., p. 103. Par exemple on retrouve Jean Guimar, de la paroisse de Rieux, archer dans le rôle de la garnison d'Auray en 1554 (Potier De Courcy, Pol, Nobiliaire..., op. cit., t. I, p. 509).

110. On retrouve en effet François Riou, archer des garnisons de Quiberon en 1552 et d'Auray en 1554 (Potier De Courcy, Pol, Ibid., t. III, p. 29).

111. SAULNIER, Frédéric, "La maison de Poix..., op. cit., p. 280.

112. Morice, Preuves, t. III, col. 1030, 1097 et 1147.

113. Ils effectuent une montre le 7 octobre 1557 à Châteauneuf et une autre en décembre à Dinan (Morice, Preuves, t. III, col. 1205-1207), « contrat de service pour les sieurs de BoisHamon " et BnF, fr. 22310, f 119 (NASSIET, Noblesse et pauvreté..., op. cit., p. 136). C'est Noël de Treal qui effectue les montres générales, le capitaine est le sieur de la Motte.

114. Bourde De LA Rogerie, "Une montre à Saint-Renan, 24 août 1557 ", Bulletin de la Société d'Archéologie du Finistère, t. 25, 1898, p. 94-108. 

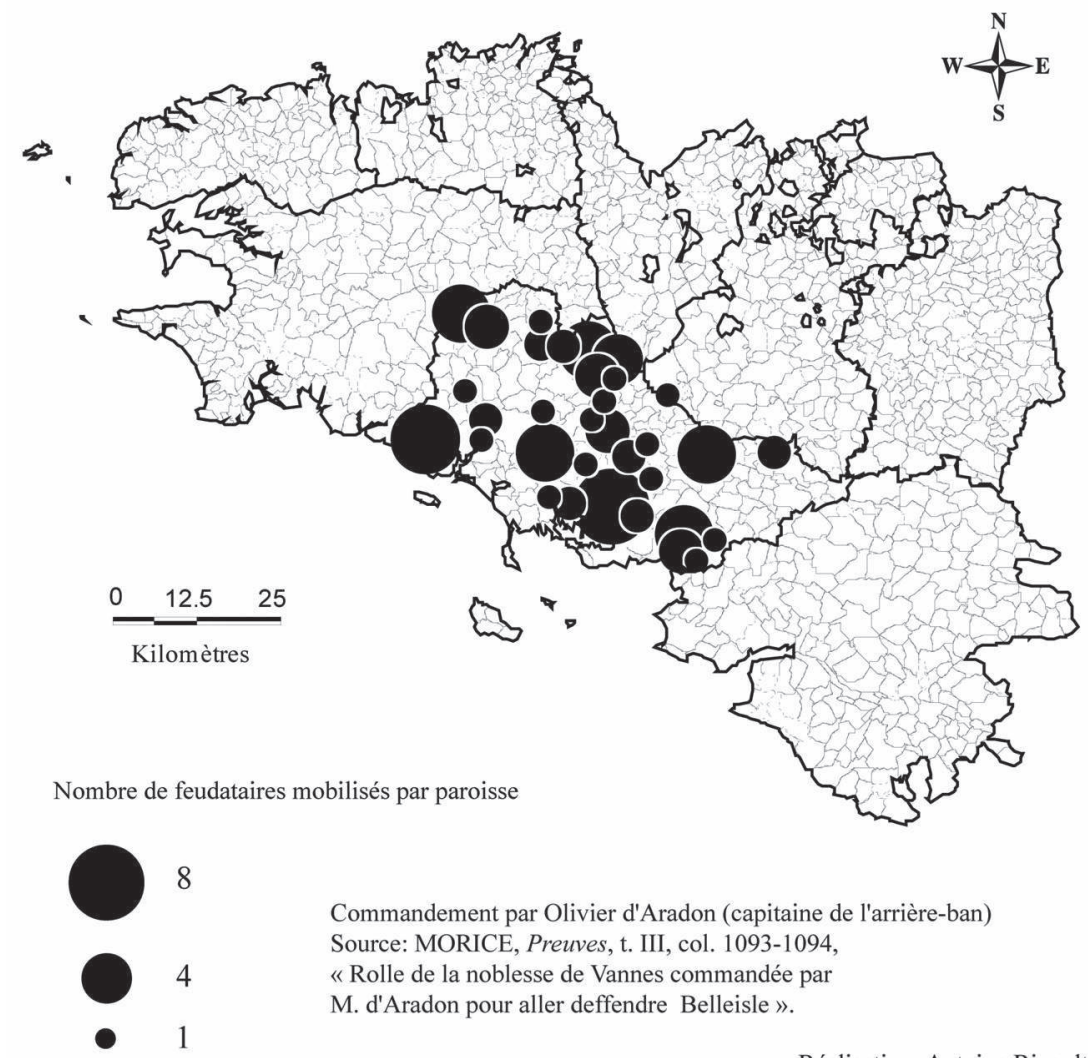

Commandement par Olivier d'Aradon (capitaine de l'arrière-ban)
Source: MORICE, Preuves, t. III, col. 1093-1094,
«Rolle de la noblesse de Vannes commandée par
M. d'Aradon pour aller deffendre Belleisle».

Réalisation: Antoine Rivault

en 1558 lors de la descente des Anglo-Flamands au Conquet. La carte ci-dessous permet d'observer une mobilisation essentiellement littorale et rurale. Ce poids de la noblesse en armes sur le littoral montre toute sa force lors de la descente du Conquet en 1558. La noblesse, rapidement au courant du débarquement à su réagir avec vigueur pour repousser l'invasion. En effet, Guillaume du Chastel, seigneur de Kersimon était le capitaine de l'arrière-ban de Léon ${ }^{115}$ et parvient à mobiliser 9000 hommes pour chasser l'ennemi ${ }^{116}$.

115. BnF, fr. $22310, \mathrm{f}^{\circ} 48$. Voir également Arch. dép. du Finistère, $32 \mathrm{~J} 2, \mathrm{f}^{\circ} 56 \mathrm{v}^{\circ}$ : « La huictiesme est un roolle des nobles sujectz au ban et arriere ban de l'evesché de Leon sur lesquels estoit capitainne le seigneur de Kersimon, dont le premier d'iceux est le sieur de Penmarch porte enseigne en datte du vingtquatriesme aoust mil cinq cent cinquante et sept."

116. La Borderie, Arthur de, et Pocquet du Haut-Jussé, Barthélemy, Histoire de Bretagne, t. v, Rennes, 1913, p. 48. De Thou parle de 7000 hommes : "Kersymon, seigneur de ce payis arriva a l'improviste avec sept mil hommes, qu'il avoit assemblez en faisant de 


\section{Figure 4 - Origine géographique des archers de l'arrière-ban du Léon en 1557}

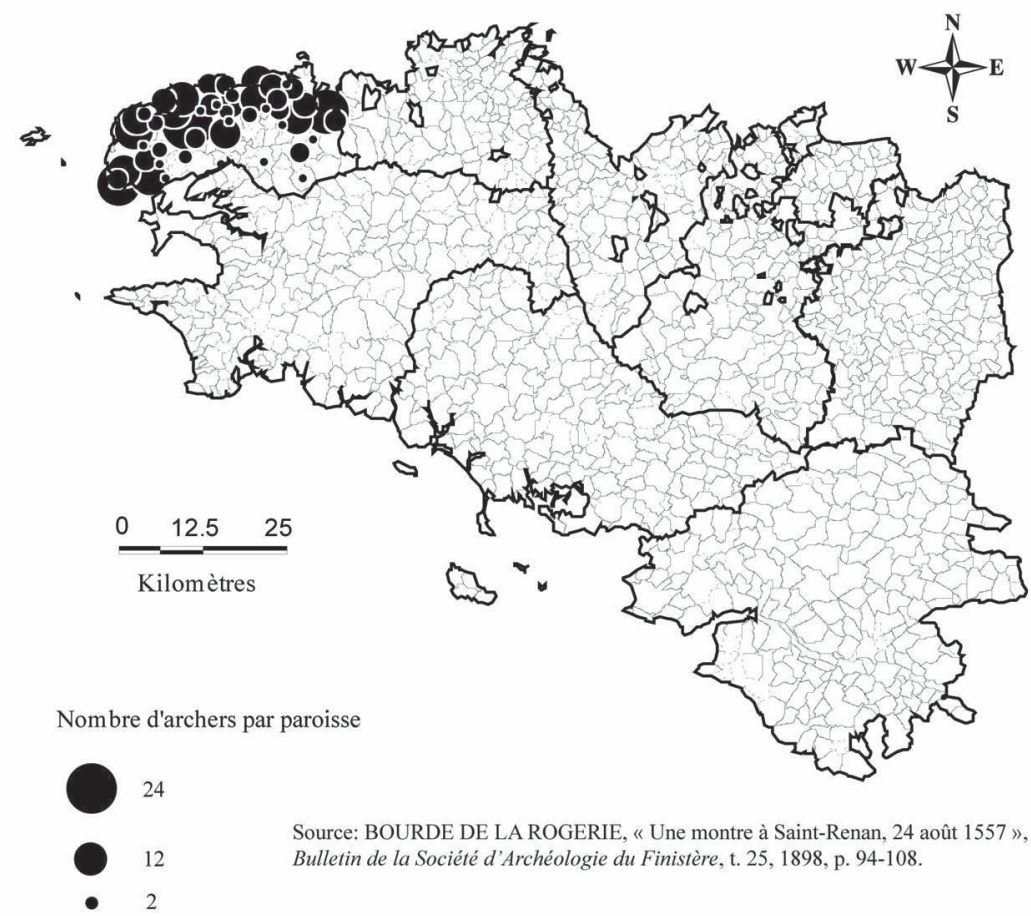

Réalisation : Antoine Rivault

En mai 1558, quarante gentilshommes de l'évêché de Rennes sont convoqués à Quintin ${ }^{117}$, en septembre, le duc d'Étampes convoque les arrière-bans de Rennes, Nantes, et Saint-Brieuc à Lesneven car les Anglais sont devant Le Conquet ${ }^{118}$. Parfois ce sont de très petites unités qui sont mobilisées. En 1560, seulement 12 gentilshommes de la juridiction de Hennebont tiennent garnison au château de la ville ${ }^{119}$.

grands feux dans la campagne pour servir de signal " (DE THOU, Jacques-Auguste, Histoire universelle depuis 1543 jusqu'en 1607, t. III, Londres, 1734, p. 242-243).

117. MoRICE, Preuves, t. III, col. 1220.

118. NASSIET, Michel, Noblesse et pauvreté..., op. cit., p. 136. L'ensemble de l'arrière-ban de Rennes n'est pas à Lesneven, une partie est convoquée à Nantes (BnF, fr. 22310, $\mathrm{f}^{\circ}$ 143-144). Le Conquet se trouve à la pointe nord-ouest de la province, Lesneven est situé au nordest du Conquet. Lors de la convocation, le duc d'Étampes en écrit au roi et au cardinal de Lorraine (BnF, fr. 5131, $\mathrm{f}^{\circ}$ 43. Lettre du duc d'Étampes au cardinal de Lorraine, Lesneven, 15 septembre 1558). Lettre du même à Henri II, Lesneven, 13 septembre 1558 (Ibid., f ${ }^{\circ}$ 45). 119. $\mathrm{BnF}$, fr. $22310, \mathrm{f}^{\circ} 149$. Seulement 2 habitants de la ville renforcent ce corps de garde en servant en tant qu'arquebusiers à cheval. 
Au début des guerres de Religion, en 1562 et 1569, l'arrière-ban de l'évêché de Saint-Malo est mobilisé sur l'estuaire de la Loire, en garnison sur la rive nord, à Lavau ${ }^{120}$. En 1562, une compagnie sous les ordres des capitaines Kergouat et Kergouanton est assignée à la garde de Port-Blanc ${ }^{121}$. En décembre 1567, Julien du Breuil reçoit l'ordre de Bouillé d'" envoyer lesdits gentilshommes, pour le service de Sa Majesté, dans la ville de Fougères " et d'y tenir garnison ${ }^{122}$. En février 1568, le même capitaine doit "faire une levée de matelots et faire marcher les gentilshommes de l'arrière-ban de l'évêché de Saint-Malo ${ }^{123}$ ". Le 22 février, il reçoit l'ordre de " couper le chemin à cinquante chevaux des ennemis, qui étoient sur la route ${ }^{124}$ ". Puis, les gentilshommes furent chargés de veiller à la bonne application de l'Édit de Longjumeau (23 mars 1568) et Bouillé organisa dans les nombreuses villes de Bretagne des garnisons de feudataires " commis par votredite majesté en chacune des villes de ce gouvernement pour avoir l'oeil a l'observation d'iceulx ecdictz ${ }^{125}$ ". Suite aux troubles de la surprise de Vitré en février 1574, une compagnie de 30 soldats de l'arrière-ban de Rennes est mise en garnison dans la ville dès le mois de mars ${ }^{126}$. En 1577, tous les arquebusiers de l'évêché de Rennes tiennent garnison à Fougères face aux agissements du roi de Navarre en Normandie. Comme toutes les places fortes ne disposent pas de mortes-payes ou de garnisons de gens de guerre, l'arrièreban sert à combler ce manque et mobilise, même en temps d'accalmie, les gentilshommes du duché ${ }^{127}$. Ainsi, Bouillé demande à Julien du Breuil, lieutenant du sieur de Pontecroix en la capitainerie de Dinan, de " s'y tenir, faire sa résidence et prendre garde et avoir l'œil soigneusement ${ }^{128}$ ".

Les gentilshommes peuvent également assister l'armée régulière en campagne. Mais la noblesse était plutôt réticente face à ce service exercé à l'extérieur de la province. Ainsi, le duc d'Étampes déplore en 1562 que

120. NASSIET, Michel, Noblesse et pauvreté..., op. cit., p. 136. et « La noblesse en France..., op. cit., p. 104.

121. Morice, Preuves, t. III, col. 1304. Kerguanton avait déjà organisé la défense de Port-Blanc en 1554 (BnF, fr. 22310, $\mathrm{f}^{\circ}$ 40, " Requeste des seigneurs de Kermorran et de Kerguanton à l'effet d'obtenir artillerie, poudres et munitions pour la garde de Portblanc, du 26 avril 1554 »). Kerguanton est aussi capitaine de 100 pistolliers au régiment de Martigues.

122. SAINT-Pern, Revue Historique de l'Ouest, année 12 (1896-Documents), p. 225-262, 19 décembre 1567.

123. Ibidem, 16 février 1568.

124. Ibid.

125. Lettre de Bouillé à Charles IX, Bouillé, 25 juin 1568 (BnF, fr. 15546, fํㄹ).

126. Rôle de la compagnie de Christophe de Poix (SAULNIER, Frédéric, "La maison de Poix..., op. cit., p. 282-283).

127. Par exemple, en 1553, des gentilshommes de l'évêché de Saint-Brieuc tiennent garnison à la Roche-Guyon pour " la garde du château » (MoRIcE, Preuves, t. III, col. 1097-1098 : "Garnison de la Roche-Gouyon ").

128. «Un brevet donné par ledit sieur de Bouillé audit Julien du Breil, sieur du Pontbriand, lieutenant du sieur de Pontcroix en la capitainerie de la ville de Dinan, pour s'y tenir, faire sa résidence et prendre garde et avoir l'œil soigneusement ; ledit brevet, en date du $2^{\mathrm{e}}$ avril 1577 » (SAINT-PERn, Revue Historique de l'Ouest, année 12 (1896 - Documents), p. 225-262). 
les " gens de ce pais servans a l'arriereban, duquel deppend tout la plus grande force que je y aye ou la meilleure partie, ne me feront jamais faulte au service qu'ilz vous doyvent, mais de m'en assurer hors le pais je ne puis pour la difficulté et protestation qu'ilz m'en ont faicte sur leurs privileges ${ }^{129}$ ". Étampes en fait part à Antoine de Bourbon : " quant aux autre forces du pais, elles y sont par forme d'arrierebans qui ont tel soing et regard d'entretenir leurs privilleiges qu'il me faudroit les combatre pour les faire sortir ${ }^{130}$ ". Le gouverneur écrit au roi que " la pluspart des arrierebans [...] n'eussent voulu sortir du pays ». Le gouverneur, ne voulant pas manquer à son devoir militaire rassure le roi en lui écrivant qu'il " en avoys levé quelques autres ", car dans le même temps " tous nos voysins en armes même les anglois [...] font grand monstre de preparatifs ${ }^{131}$ ". Il apparaît dans les sources que les feudataires se réfèrent à leurs " privilèges " relatifs au service armé, qui ne peut être exercé en dehors des frontières du duché de Bretagne. À l'inverse, le neveu et successeur du duc d'Étampes, le vicomte de Martigues, "se fit fort aymer à la Noblesse de là ; si bien qu'on luy donna ceste reputation d'avoir eu le credit de l'avoir faicte sortir hors de son pays et de l'avoir menée où bon luy sembloit et depaysée, ce que Gouverneur de long-temps n'avoit faict, ny sceu faire. Aussi il la menoit au combat bravement, luy tousjours à la teste et des premiers, comme il fit au passage de la Riviere de Loyre, où il chargea Monsieur d'Andelot et ses trouppes et en desfit aucunes ${ }^{132}$ ". En effet, la compagnie de Tanguy de Rosmadec, le capitaine de l'arrière-ban de Cornouailles, est mobilisée avec Martigues. On la retrouve au combat de la levée en 1568 puis dans le régiment de Martigues ${ }^{133}$. Ce "régiment " est composé de troupes payées par l'extraordinaire des guerres mais dont les capitaines sont très souvent des capitaines de l'arrière-ban breton. Les capitaines pouvaient ainsi se servir d'un vivier de recrutement au sein de la noblesse. François de Guémadeuc (capitaine de la noblesse de Dol) a ainsi pu mobiliser certains nobles au sein de son arrière-ban en armes ${ }^{134}$. La distribution des lettres de commission de capitaine pour ce type de troupes s'inscrit également dans les stratégies nobiliaires de Martigues, afin de s'attacher la noblesse bretonne à la tête d'emplois militaires locaux. Le gouverneur a allègrement puisé dans les rangs des officiers militaires de la province pour lever rapidement des compagnies, accentuant de fait la spécialisation de certains dans le métier des armes.

129. Lettre du duc d'Étampes à Catherine de Médicis, Nantes, 17-19 juin 1562 (LuBLINSKAYA, Aleksandra, Documents..., op. cit., p. 69).

130. Lettre du duc d'Étampes à Antoine de Bourbon (lieutenant-général du royaume et donc chef de l'armée du roi en son absence), Nantes, 18 juin 1562 (Ibid., p. 73).

131. Lettre du duc d'Étampes à Charles IX, Nantes, 7 juillet 1562 (BnF, fr. 15876, f 209.

132. BRANTÔME, Discours sur les colonels de l'infanterie française, édité par Étienne VAUCHERET, Paris-Montréal, 1973, $\mathrm{f}^{\circ} 192 \mathrm{r}^{\circ}$.

133. Régiment de Martigues, 1568 (BnF, fr. 3898, $\left.\mathrm{f}^{\circ} 228 s q q\right)$.

134. Comptes de Jean Avril, trésorier des États (1562-1563) (Arch. dép. d'llle-et-Vilaine, C 2859-2861). 
Ainsi, en 1577, les États de Bretagne remontrent que Martigues avait levé en 1567 une armée " où se trouverent plusieurs nobles d'icelui pays, lesquels y firent le service volontairement sans en avoir tirer aucune solde, et les autres non volontaires desdites armées furent a plus de 2000 hommes pour chacun voyage soldoyés hors le dit pays le temps de trois mois chacun $^{135}$ ". On comprend donc bien que Martigues ait réussi à faire sortir des nobles de la province, tant volontaires que non, ceux qui ne le furent pas appartiennent à des compagnies de l'arrière-ban puisqu'ils sont payés pour trois mois. À nouveau, en mars 1569, lorsque Martigues envoie de l'artillerie en Bas-Poitou, les compagnies de l'arrière-ban sont mobilisées, et les gentilshommes de l'archidiaconé de Porhoët ont sûrement fait partie de l'escorte ${ }^{136}$. En 1574, on apprend que "la noblesse dudit pays a été contrainte de faire plusieurs grands frais pour s'équiper en guerre afin de se trouver aux camps de Normandye et de Poitou " sous les ordres du duc de Montpensier (gouverneur de Bretagne de 1569 à 1582) ${ }^{137}$.

\section{«La diversité des opinions"}

Qu'en est-il des nobles protestants devant servir au sein de l'institution? Les montres et rôles sont des sources assez muettes sur ce sujet. Il est probable que certains continuent de se présenter aux rôles préparatoires pour recenser leurs biens et être en règle avec la juridiction locale ; mais lorsque les levées sont militaires, pour aller patrouiller et surveiller les calvinistes, beaucoup préfèrent tenter de se fondre dans la masse des absents, des malades et des exemptés. Au cœur de la guerre, quand l'arrière-ban est mobilisé pour combattre les huguenots, certain refusent de venir se ranger du côté des catholiques et de participer à une guerre qualifiée d'injuste et en manque de légitimité ${ }^{138}$. L'engagement protestant d'une partie de la noblesse peut expliquer le manque de confiance des gouverneurs vis-àvis des montres générales, ils préfèrent s'appuyer sur des "guerriers de Dieu " dont ils ont l'assurance d'une catholicité approuvée. Au début des troubles, le port d'armes des nobles a inquiété le pouvoir central. En effet, le gouverneur se méfie de l'arrière-ban car il légalise le port d'armes à « une noblesse corrompue ${ }^{139}$ ".

Ainsi, après la conjuration d'Amboise, Bouillé déplore qu'environ 300 gentilshommes armés de l'évêché de Rennes enrôlent tous ceux qui les veulent suivre, leur promettant « le pillage des églises et des richesses de

135. CALAN, Charles de La Lande de, Documents inédits relatifs aux États de Bretagne de 1491 à 1589, Société des bibliophiles bretons et de l'histoire de Bretagne, 1908, t. II, p. 105. 136. Sevegrand, Gérard, "Le ban et l'arrière-ban de Porhoët..., op. cit., p. 75-76.

137. Arch. dép. d'Ille-et-Vilaine, C 2641, p. 130.

138. De Thou, Jacques Auguste, Histoire universelle depuis 1543 jusqu'en 1607, t. III, Londres, 1734, p. 193-196 : refus des huguenots de venir servir l'arrière-ban mobilisé par Antoine de Navarre en 1562.

139. Le Bossu, Troisième devis du catholique et du politique, Nantes, 1589, p. 92 (Arch. dép. d'Ille-et-Vilaine, 1 F 687). 
France [... et qu'après ils viendront faire autant en Bretagne ${ }^{140}$ ". Le lieutenant général Bouillé observe que les " plus riches de ce pays se vont mettre avecques ces troupes qui s'en vont en armes à Orleans et disent par la que c'est pour aller au service du Roi, et prennent le chemin de Laval ${ }^{141}$ ". Le but d'une telle levée de gentilshommes en Bretagne était de rejoindre Orléans comme pour continuer l'affaire d'Amboise. Il fallait pour le pouvoir royal en Bretagne veiller au maintien de l'ordre lors du retour dans la province de ces protestants. Lorsque Souleville reçoit le commandement d'une compagnie de 50 arquebusiers à cheval en avril 1560, pour encadrer les retours d'Orléans, le duc d'Étampes précise bien auprès des soldats qu' ils n'ayent a porter harquebuse ne pistollets synon ceulx qui auront certification de vous d'estre de vostre compagnie et de vous votre lieutenant ou cornette et en venant a vous ne se retirant en leurs maisons ils les porteront desmontées et n'en pourront tirer à gibier ny aultres choses deffendues par le Roy $^{142}$ ". Même pour ses propres troupes, le gouverneur est méfiant et tente de limiter le plus possible le port des armes afin d'éviter tout débordement de violence. Peu après la répression de la conjuration d'Amboise, il a également fallu éviter d'éventuels exils du royaume. Ainsi, en avril 1560, les gentilshommes de l'arrière-ban de Nantes sont convoqués pour surveiller et contrôler la côte de Rais, car il circule des rumeurs d'embarquement de protestants à partir de celle-ci, notamment pour l'Angleterre. Ils reçoivent l'ordre du gouverneur de capturer ceux qui tenteraient la traversée et de les emprisonner " au chasteau de Nantes ou autres forteresses ${ }^{143}$ ".

La même année, Christophe du Maz, sieur du Brossay-Saint-Gravé, huguenot avéré et capitaine de l'arrière-ban de Nantes, est accusé de violence à l'encontre d'un paysan ${ }^{144}$. En 1561, le duc d'Étampes se trouve confronté à un manque de troupes et reste très prudent quant à l'armement de l'arrière-ban. Il rapporte au roi que " de s'aider de ceulx du pais les ungs contre les aultres se seroit a livrer le feu a la division qui est assez grande ${ }^{145}$ ". Le gouverneur reste très prudent vis-à-vis des feudataires car " il y en a de si diverses humeurs " qu'il y a " grand doute de leur metre forces entre leurs mains ${ }^{146}$ ". Ainsi, armer des feudataires de la " nouvelle opinion " pourrait se retourner contre le pouvoir royal. Le gouverneur est un des ardents critiques du service. Il écrit ainsi au roi la même année : "Et de la noblesse du pais elle est si lasse de ce que depuis deulx ans il

140. MoRICE, Preuves, t. III, col. 1232-1235.

141. Lettre de Bouillé au duc d'Étampes, Rennes, 16 avril 1559 (avril 1560) (MoRICE, Preuves, t. III, col. 1235).

142. Acte du Duc d'Étampes, Rennes, 11 avril 1559 (avril 1560) (BnF, fr. 22310, f ${ }^{\circ} 124$ ).

143. "Commission au Sieur de la Frudiere pour empêcher les Calvinistes de s'embarquer à la côte de Raix [...] comme le Roy ai esté adverti que aucuns personnages avoir déliberé s'embarquer pour faire voile et passer la mer et donner advertissement aux estrangers, dont pourroit venir plusieurs inconveniens..." (MoRICE, Preuves, t. III, col. 1231).

144. VAURIGAUD, Benjamin, Essai sur l'histoire des Églises réformées de Bretagne, 1535-1808, t. I, p. 50. Voir également sur cet individu : CASTELnau, Michel de, Mémoires, t. II, p. 585.

145. Lettre du duc d'Étampes à Charles IX, L’Aigle, 31 janvier 1561 (BnF, fr. 3186, f $\left.{ }^{\circ} 33\right)$.

146. Lettre du duc d'Étampes à Charles IX, L'Aigle, 31 janvier 1561 (BnF, Ibid., f $\left.{ }^{\circ} 35\right)$. 
n'a esté mois qu'elle n'aict esté travaillée pour telles choses et si sont les oppinions permises qu'il y en a bien peu qui ne soient affectionnez d'une part ou d'aultre ${ }^{147}$. " Cependant, on peut nuancer la portée de ces propos. Si le duc d'Étampes parle ainsi, c'est afin de justifier l'envoi de nouvelles troupes à entretenir en garnison dans les villes bretonnes, demande faite à la monarchie et qu'il renouvelle fréquemment.

En 1562, un nombre important de protestants bretons part rejoindre l'armée de Coligny à Orléans ${ }^{148}$. Leur retour en Bretagne mobilise l'ensemble des autorités. Bouillé " $s$ 'est retiré pour se transporter sur la frontière comme il a dit le plus fort et mieux accompagné qu'il pourra ${ }^{149}$ ". Deux jours plus tard, le parlement de Bretagne décide qu' "il estoit requis envoyer hommes expres sur les frontieres de ce pais pour scavoir en quels lieux etoient lesdits ennemis, leurs forces et quels chemins ils prendroient ${ }^{150}$ ". En effet, le duc d'Étampes se plaint que " notre pais se remplist de gens tant de ceux qui reviennent d'Orleans que d'autres et mesmes que j'ay depuis entendu que encores qu'ilz disent y revenir pour chercher du repoz, je suis adverty de beaucoup d'endroictz qu'il est pour y remuer mesnage ${ }^{151}$ ". Pour éviter tout débordement, le sieur de Souleville est de nouveau convoqué avec sa compagnie $^{152}$. D'autant plus que les « secours d'Orléans " concernent également les gentilshommes d'Anjou, du Poitou, du Maine et de la Normandie et que « la pluspart des sieurs sont armés ». Ainsi le duc d'Étampes doit convoquer " les sieurs de Kersymon et de Thiouarlen audit pais [...] avec cent harquebuziers a cheval et une enseigne de gens de pied pour avec ce qu'ilz pourront amasser des arriere bans " pour aller défendre la " frontière " de Normandie et éviter la prise de Pontorson ${ }^{153}$. Mais Bouillé déplore déjà l'état déplorable de l'arrière-ban en conseillant au duc d'Étampes : " Quant aux arrierban de ce pais n'en faictes plus d'estat car il n'y demeure plus rien de service tant les gaillars hommes s'en vont avec les aultres ${ }^{154}$."

147. Lettre du duc d'Étampes à Charles IX, Lamballe, 18 avril 1561 (BnF, Ibid., f ${ }^{\circ} 88$ ).

148. François d'Andelot, frère de Coligny, est ainsi du trajet. Son autre frère, Odet de Coligny, est dans la ville depuis le 22 août 1562 (Arch. nat., J 969, f ${ }^{\circ}$ 2).

149. Arch. dép. d'Ille-et-Vilaine, 1 Bb 755, f ${ }^{\circ}$ 21, 6 mars 1562 (registres du parlement de Bretagne).

150. Arch. dép. d'Ille-et-Vilaine, Ibid., f ${ }^{\circ}$ 23, 9 mars 1562.

151. Lettre du duc d'Étampes à Charles IX, Nantes, 19 juillet 1562 (BnF, fr. 15876, f ${ }^{\circ}$ 293).

152. Lettre du duc d'Étampes à Souleville, Nantes, 16 juillet 1562 (MorICE, Preuves, t. III, col. 1313).

153. Lettre du duc d'Étampes à Charles IX, 10 août 1562 (BnF, Ibid., f f 389). On retrouve la crainte des gentilshommes des provinces voisines dès le début des troubles. Le duc d'Étampes rapportait ainsi en 1561 que « il s'est rendu en ceste ville quelque trouppe de gentilshommes des pays d'Anjou et de Poictou desquelz l'on avoyt mauvaise oppinion et que pour la reformation de la religion ilz voulussent entreprendre quelque chose contre le service du roy " (Lettre du duc d'Étampes à Catherine de Médicis, Nantes, 25 septembre 1561. BnF, fr. 15875, f $\left.{ }^{\circ} 192\right)$.

154. Lettre de Bouillé au duc d'Étampes, Saint-Julien-de-Vouvantes, 23 juin 1563 (BnF, fr. 15881, $\left.\mathrm{f}^{\circ} 183\right)$. 
En 1563, face aux rumeurs de débarquement anglais, le duc d'Étampes doit mettre la province en défense. Pour cela, il pourrait s'appuyer sur l'arrièreban ou les francs-archers mais ceux-ci, " tant pour leur deffault d'experiance que pour la diversité des opinions ", suscitent la méfiance du gouverneur qui demande à la reine de lui envoyer plutôt " trois ou quatre enseignes de voz vieilles bandes des mieux vivantes et traitées pour en mettre dans voz places de Brest et Sainct Malo ${ }^{155}$ ». En 1566, Bouillé se plaignait du " port des harquebuzes et pistolles " et de l'alliance des huguenots bretons avec les Anglais qui " sont bort a bort de ceste coste pour les receuillir ou secourir ${ }^{156}$ ». En 1568, François d'Andelot, qui s'était retiré sur ses terres de Bretagne, rassembla le plus de protestants de la province qu'il pouvait, pour prêter mainforte à son frère, l'amiral de Coligny. Le vicomte de Martigues rapporte qu'«il y en a aussi quelques ungs de nouvelle religion qui me sont depuis venu dire qu'ils avoient entendu qu'il y avoit des forces qui me suyvoient et que j'estois venu pour leur courir sus. Je leur ay respondu comme audit sieur Dandelot que je n'avois charge ni commandement de Votre Magesté que de maintenir toutes choses en repos et de faire observer vos esdicts. Toutes fois (avec leur bonne myne) j'ay bien descouvert qu'ils veullent reprendre les armes et pour tout certain ils ont faict advertir depuis trois ou quatre jours par leurs églises tous les leurs de se tenir prests marcher quand ils seront mandés ${ }^{157}$ ". En effet, Andelot, qui était à Vitré, appela la noblesse protestante de Bretagne à soi ${ }^{158}$. Martigues observe qu' “ il est vray que ceulx de la dicte religion de deçà ne font encore semblant de rien. Ores que je sache bien qu'ils sont tous prests, en allant et venant ordinairement de Province en aultre, en visitant souvent ledict sieur Dandelot ${ }^{159}$ ". François de La Noue, François d'Acigné, sieur de Montejean, et Charles de Beaumanoir, baron de Lavardin, et Christophe du Maz, sieur du Brossay Saint-Gravé (ancien capitaine de l'arrière-ban de Nantes) sont les grands chefs qui mènent "le contingent des réformés de Bretagne " sous le commandement d'Andelot ${ }^{160}$. Les autorités militaires bretonnes sont d'autant plus inquiètes que, comme le dit bien Bouillé, la division touche aussi les parlementaires. En effet, " les connivences et dissimulations de quoy ceulx de la robbe longue usent ne font que croistre le cœur aux seditieulx et rebelles ${ }^{161}$ ".

155. Lettre du duc d'Étampes à Catherine de Médicis, Saint-Malo, 14 juillet 1563 (BnF, Ibid., $\mathrm{f}^{\circ}$ 190).

156. Lettre de Bouillé au roi, Vannes, 4 avril 1566 (BnF, fr. 15882, $\mathrm{f}^{\circ} 273$ ).

157. Lettre de Martigues à Catherine de Médicis, Nantes, 26 juillet 1568 (LA BoRDERIE, Arthur de, " Documents sur l'histoire de Bretagne au Xvi e siècle, tirés des archives impériales de Russie ", Bulletin de la Société archéologique et historique de Nantes et de LoireAtlantique, 1877, t. 16, p. 56).

158. AuBigné, Agrippa d', Histoire universelle, Éd. André Thierry, Genève, Droz, 1981-2000, t. III, L. v, p. 15-16.

159. Lettre de Martigues au roi, Nantes, 27 juillet 1568 (LA BoRDERIE, Arthur de, " Documents sur l'histoire..., op. cit., p. 59).

160. HAUSER, Henri, François de la Noue (1531-1591), Paris, Hachette, 1892, p. 17. Voir également DE THou, Jacques Auguste de, Histoire universelle..., op. cit., t. v, p. 529.

161. Lettre de Bouillé à Catherine de Médicis, Rennes, 7 juin 1568 (BnF, fr. 15546, f ${ }^{\circ}$ 170). 
Dans la province, les nobles protestants en armes maintiennent un état de peur et de suspicion grâce à d'heureuses entreprises qu'ils mènent avec succès mais qui sont tout de suite étouffées par les forces royales. En 1574, des gentilshommes sous le commandement de "Monmartin ${ }^{162}$ le trestre, qui avoit le jour gras soupé au chasteau avesques Monsieur de la Feillée ${ }^{163}$ " s'empare du château de Vitré ${ }^{164}$. Le sieur de Brossay SaintGravé est également de l'entreprise. Le jeudi 17 janvier 1577, le jour de la Saint-Antoine, en temps de paix, "les sieurs de Lavigne ${ }^{165}$, Kermassonet, Porzcarie, les trois frères Loquevolay " de l'évêché de Vannes se rassemblent en une petite troupe de "trente-six à cheval bien montez et quarante-cinq hommes de pied harquebusiers, entre lesquels estoient certains gascons " et surprennent la place forte de Concarneau ${ }^{166}$. Agrippa d'Aubigné, quant à lui, ne mentionne que vingt-deux soldats ${ }^{167}$. Le lieutenant de la place, le sieur du Fresq, " avoit été tenu et réputé huguenot ". L'auteur ne sait si celui-ci était d' " intelligence " avec les protestants qui lancèrent l'opération, mais celui-ci, le jour de la surprise, était dans une "sienne maison distante deux lieues de ladicte forteresse ». La populace, qui avait déjà tenté d'avertir les gouverneurs que le lieutenant était " suspect de la religion ", retourna sa fureur contre cet homme, et " luy avoient couru sus, et iceluy meurtri et saccagé ${ }^{168}$ ". "Les sieurs de Kymerk, son frère le marquis, les sieurs de Prat-Maria, de Bodigneau et plusieurs autres gentilshommes du quartier " organisent alors la noblesse en armes ainsi que les soldats des communes pour reprendre la ville. Lors de l'assaut, les paysans «tirent fort bien de l'arbaleste " et les " gentilshommes et gens des villes, bourgs et bourgades maritimes [...] usent d'arquebuses ${ }^{169}$ ". Pour avoir si bien réagi à l'alarme, le capitaine de l'arrière-ban de Cornouaille, Nicolas de Tyrvalen, sieur de Kerharo, est récompensé par Henri III en personne et reçoit une retenue de gentilhomme de sa chambre, une pension de 300 ou 400 livres tournois et l'inscription sur l'état des pensionnaires du duché de Bretagne ${ }^{170}$. Avec cet épisode, il apparaît que ces nobles protestants sont bien armés et en nombre important. Ils devaient sûrement le service féodal au sein de l'arrière-ban. Cependant, la majorité des nobles

162. Jean du Matz, seigneur de Montmartin et de Terchant.

163. Guillaume de Rosmadec, chevalier de l'ordre du roi, gouverneur de Vitré.

164. René Le Cocq, bourgeois de Vitré nous rapporte avec détails l'épisode de la surprise du château par les huguenots (Arch. dép. d'Ille-et-Vilaine, $40 \mathrm{~J}$ 161, f ${ }^{\circ} 87$ ).

165. Nicolas de Baud, seigneur de La Vigne-le-Houlle, dit le capitaine Kermat, gentilhomme protestant.

166. « Ample discours de la surprise de Concq, près de vannes, pays de Bretaigne par ceux de la Religion " (CIMBER et DANJou, Archives curieuses de l'histoire de France, 1836, t. 9, p. 167-176).

167. Aubigné, Agrippa d', Histoire..., op. cit., t.v, L. VIII, chap. vIII, p. 178, La Vigne « n'eut moyen de mettre ensemble avec Kermaçonnet que vingt deux soldats".

168. "Ample discours de la surprise de Concq, près de Vannes, pays de Bretaigne par ceux de la Religion » (Cimber et DANJOU, op. cit., p. 169).

169. Ibid.

170. Lettre de Henri III au duc de Montpensier, Chenonceaux, 10 mai 1577 (BnF, fr. 3344, $\left.\mathrm{f}^{\circ} 3\right)$. 
qui reste fidèle à la monarchie apparaît dans bien des cas comme un outil nécessaire pour le maintien de l'ordre intérieur. De plus, la rapidité d'action de l'institution militaire eut raison de la surprise et empêcha tout secours rochelais ${ }^{171}$.

\section{Une source de contraintes pour les uns, de confiance pour les autres}

Le service des feudataires pouvait également dépasser le temps trimestriel imparti. Ainsi, en 1573, l'arrière-ban est mobilisé en garnison à Bréhat pendant quatre mois ${ }^{172}$. Nous apprenons que lors de la levée de 1574 , "le ban et arrière ban ont été mandés et levés actuellement audit pays, et ont fait le service à leurs depens par l'espace de plus longtemps qu'ils ne sont tenus, enquoy ils ont fait grandes dépenses, et en sont grandement mal aisés ${ }^{173}$ ". On comprend bien que le service est contraignant pour les feudataires, surtout pour les plus humbles de ceux qui sont mobilisés en personne. Pendant qu'ils sont en service, ils ne peuvent s'occuper de leurs affaires et le service coûte cher aux astreints car il leur faut entretenir les armes, prévoir leur propre ravitaillement, nourrir les chevaux quand ils en ont. C'est ce que remarque Claude Haton lorsqu'il déclare des feudataires qu' " ilz furent contrainctz plus qu'ilz ne voloient " de " la contribution de l'arriere-ban ${ }^{174}$ ». Certains voudraient donc bien se dégager de ce service.

Il faut donc distinguer les effectifs recensés lors des montres de ceux qui servent réellement en armes. Beaucoup plus d'absents sont présents sur les registres des montres en armes que de celles en robe. Ce qui a amené La Noue à dire qu'il " y a grande difference entre les trouppes, quand elles comparoissent aux monstres, qui se font aux villes principales, ou quand elles marchent pour aller où il est commandé. Car aux monstres, on y void souvent des gentils-hommes en bon equipage, qui vont seulement pour exempter leur fief de saisie, et pour dire qu'ils sont appareillez à faire service $^{175}$ ". Les défaillances sont relevées dans les registres des commissaires mais, avant les troubles religieux, celles-ci n'influaient pas sur la sécurité publique. Désormais, le pouvoir royal s'efforce à ce que les feudataires soient bien présents et armés, surtout en cas de crise intérieure. Ainsi,

171. "Ample discours de la surprise de Concq, près de vannes, pays de Bretaigne par ceux de la Religion" (CIMBER et DANJou, Ibid., p. 167-176).

172. «La septiesme du onziesme juin mil cinq cents soixsante et treze est autre certifficat dudict Quergouanton-Loz, que de ledict Jan Courson, sieur de Quernescop avoit faict le service au Roy les quattre mois lors derniers, en la retenue de l'isle de Brehat : Ledict acte deubmant signé et garanti " (CouRson, Robert de, Recherches historiques sur la Maison de Courson, 1881, p. 87-90).

173. Arch. dép. d'Ille-et-Vilaine, C 2641, p. 129.

174. Mémoires de Claude Haton (1553-1582), Laurent BouRQuin (éd.), Collection de documents inédits sur l'Histoire de France, Paris, Éd. du C.T.H.S, 2002-2007, vol. 2, 1569 (§ 11). cité par BouRQuin Laurent, "La fiscalité, facteur de politisation dans les Mémoires de Claude Haton ", Parlement[s], Revue d'histoire politique 3/2010 (n HS 6), p. 157.

175. La Noue, François de, Discours..., p. 266. 
lors du service de garnison de Port-Blanc en 1562, effectué par les gentilshommes de l'arrière-ban, Claude de Boiseon précise bien à ceux-ci de " n'en bouger sans leur congié sur peine de rebellion ${ }^{176}$ ". Bouillé déplore également le manque de volonté d'une partie de la noblesse, effrayée par les coûts financiers individuels à supporter en cas de convocation extérieure aux levées habituelles. Le lieutenant général témoigne que " ceulx qu'on appelle papiste sont si cazaniez qu'il n'y en a ung seul qui voullust avoir despence ung estre pour achapter et mectre en equipage et s'en servir si affaire viend ${ }^{177}$ ». En 1578, lorsque Bouillé convoque une partie des gentilshommes de l'arrière-ban de Saint-Brieuc face à la menace protestante réunie à Alençon, sous le commandement de Henri de Navarre, il précise que " ceux qui y feront faute, je mande aux Officiers de Justice de saisir leurs terres ${ }^{178}$ ". Cela a sûrement aussi compté dans le fait qu'en 1570, le pouvoir royal ne s'appuie plus que sur ceux à qui il peut faire confiance, c'est-à-dire sur ceux dont il est sûr qu'ils se présenteront lors de la levée.

Le pouvoir royal doit aussi compter avec la durée trimestrielle du service militaire. S'il mobilise une compagnie trop tôt dans l'année et lorsqu'il n'y a pas de réels troubles, il se voit privé de ses troupes lorsqu'il aura une autre inquiétude. Certes, il peut allonger le service, mais on l'a vu, cela est mal vécu par les feudataires. C'est pourquoi, les services de garnison sont évités. Bouillé, en 1574, écrit ainsi à Souleville que les cavaliers de l'évêché de Saint-Brieuc servent pour la garde des côtes " sans qu'ils tiennent garnison affin de les soullager a la charge qu'ils se tiendront toujours prests pour marcher lorsque je les manderez et pour deffendre la coste s'il y survient quelque chose ${ }^{179}$ ". Pour les actions de dissuasion, de garnison, finalement de présence militaire et de maintien de l'ordre, la convocation au cas par cas (par compagnie) semble être le meilleur moyen pour le pouvoir royal. En effet, il peut jouer sur la durée en ayant tout au long de l'année des effectifs sur pied, et sur la nature des opérations en convoquant les troupes adéquates à la mission, comme des arquebusiers pour la défense d'une place forte ou des cavaliers pour la garde des côtes. Mais il ne faut pas croire que les feudataires ne servent que lorsqu'on les convoque; lorsque le danger se fait sentir, l'institution militaire joue son rôle fédérateur de la noblesse en

176. Morice, Preuves, t. III, col. 1304. Il faut entendre ici " sous peine [de répression de la] rébellion".

177. Lettre de Bouillé au duc d'Étampes, Saint-Julien-de-Vouvantes, 23 juin 1563 (BnF, fr. 15881, $\left.\mathrm{f}^{\circ} 183\right)$.

178. Morice, Preuves, t. III, col. 1443-1444. 13 février 1578. Les exemples peuvent être multipliés, "le sieur du Cambout leur capitaine [leur ordonne] de ne partir de soubs son enseigne sans son congé " (Arch. dép. des Côtes-d'Armor, 1 C 184 ; montre du 27 juin 1554) Ce problème de l'absentéisme des feudataires et des mesures pour le réduire est également relevé avec humour par Rabelais dans Gargantua, lorsque le roi Picrochole " feist crier par son ban et arriere ban, et que un chascun sur peine de la hart [corde] convint [se réunit] en armes en la grand place, devant le chasteau, à heure de midy " (RABElaIS, Gargantua, Paris, Gallimard, Folio classique, édition par Mireille Huchon, 19942007, p. 255).

179. BnF, fr. $22310, \mathrm{f}^{\circ} 134, \mathrm{r}^{\circ}$. 
armes. Ainsi, lors de la descente des Anglo-Flamands au Conquet le 29 juillet 1558, c'est toute la noblesse du Léon et de Tréguier qui repousse les envahisseurs à la mer sous le commandement de leur capitaine, Kersimon ${ }^{180}$, et fait ainsi preuve de sa réelle efficacité et rapidité d'action ${ }^{181}$. Mais, face à la multitude de descentes en 1558, le duc d'Étampes déplore la situation de " la noblesse qu'il n'y a plus moien de retenir, encores que plusieurs ayant bonne volonté, mais ilz n'ont plus de moien de soubstenir la despence et tout ce qui nous est plus necessaire pour aller promptement aux lieux ou l'ennemy fait descente ${ }^{182}$ ". Car " la cavallerye est ce qu'ilz craignent le plus " et l'arrière-ban cavalier est la meilleure arme contre ces débarquements. Le souvenir de cet épisode resta vivace pendant toutes les guerres et en 1568, à l'annonce du passage de l'armée de mer de La Rochelle au large du Conquet, "l'on étoit accouru de toutes parts en armes, sur l'avis qu'il y avoit une flotte de corsaires en mer $^{183}$ ".

Avec les débuts des troubles entre catholiques, la charge de capitaine de l'arrière-ban d'un évêché est un moyen pour le pouvoir royal de s'assurer des fidélités d'une "noblesse moyenne " en Bretagne et de profiter de ses réseaux au sein de la petite gentilhommerie locale. Ainsi, Mathurin de la Roche-Saint-André obtient sa charge de capitaine de l'arrière-ban de l'évêché de Nantes vers 1574 et devient un fidèle serviteur de la cause royale. Le roi correspond personnellement avec ce dernier et témoigne publiquement de sa " fidélité " en 1576. En 1580, c'est Henri III qui lui écrit afin qu'il lève et mobilise les gentilshommes de l'évêché de Nantes, face au danger de la garnison de Montaigu ${ }^{184}$. En 1585, pour le siège de Blain, Henri III demande au lieutenant général La Hunaudaye, qui connaît bien la noblesse de l'évêché de Rennes, d'y mener " aussy le plus grand nombre de la noblesse de votre charge que vous pourrez ${ }^{185}$ ". C'est-à-dire que le roi fait appel aux propres fidélités de son lieutenant général pour mobiliser les nobles capables. Face aux troupes de Condé et aux 200 ou 300 chevaux du vicomte de Rohan, Henri III demande à la noblesse de Bretagne de s'assembler sous les ordres de Mercœur, mais cela sans aucune convocation officielle de

180. "Guillaume du Chastel, seigneur de Kersimon, capitaine de l'arrière-ban de Bretagne ", 1557 (BnF, fr. 22310, f ${ }^{\circ}$ 120). Il est le capitaine de l'arrière-ban de l'évêché de Léon et appartient à la famille de Tanguy du Chastel, le meurtrier de Jean sans Peur et proche de Charles VII.

181. OGÉE J.-B., Dictionnaire historique de Bretagne, t. II, 1845, p. 328, ARGENTRÉ Bertrand d', Histoire de Bretagne, 1588, p. 1052, Morice, Preuves, t. III, col. 1225-1227.

182. Lettre du duc d'Étampes à Henri II, Lesneven, 13 septembre 1558 (BnF, fr. 3151, f $\left.{ }^{\circ} 45\right)$.

183. DE Thou Jacques-Auguste de, Histoire universelle..., op. cit., t. v, p. 556.

184. Rosmorduc Georges Le Gentil (comte de), La Noblesse de Bretagne devant la Chambre de Réformation, (1668-1671), Saint-Brieuc, 1905, t. I, p. 512. Lettres du roi à la Roche-SaintAndré, 6 juillet 1580, et certificat de La Hunaudaye qui atteste que le service a bien été rendu, 6 novembre 1580. Son fils, René de la Roche est d'autant plus fidèle au roi qu'il refuse de comparaître aux montres pour la Ligue en 1595. Mathurin de la Roche-SaintAndré est sujet au ban du Poitou et à celui de Nantes en 1557 et sert dans ce dernier (LAROQue, Gilles André de, Traité de la noblesse et de toutes ses différentes espèces, Rouen, 1734, p. 142).

185. Lettre de Henri III à La Hunaudaye, Paris, 15 novembre 1585 (BnF, fr. 3309, $\left.\mathrm{f}^{\circ} 73\right)$. 
l'arrière-ban, seulement " d'assembler le plus grand nombre de ma noblesse et des forces d'icelluy pais qu'il luy [Mercoeur] sera possible pour les aller trouver et s'en saisir ${ }^{186}$ ". Après le décès de Julien du Breuil en 1587, Henri III ordonne à Mercœur de nommer le fils Breuil comme capitaine du ban de Saint-Malo ${ }^{187}$. Il s'avère alors que la charge de capitaine de l'arrière-ban, bien que moins bien prestigieuse que le commandement d'une compagnie d'ordonnance, est un instrument de récompense royale, un moyen pour le roi de s'attacher des fidèles dans une province de plus en plus touchée par la Ligue. Jean du Breuil reste en effet un fidèle de Henri III dès les débuts de la Ligue. En 1588, Mercoeur institue Gilles du Plessis, seigneur du Plessis d'Argentré, capitaine de la noblesse de Rennes. Ce dernier est toujours en poste (comme commissaire) en $1596^{188}$. Cela attesterait soit de la volonté du duc de Mercoeur de s'attacher des fidèles à des postes militaires clés avant l'entrée officielle de la province dans la Ligue (et ici contrôler l'évêché rennais réputé fidèle au roi), soit de la fidélité royale du sieur du Plessis qui est resté à son poste pendant la Ligue.

En 1570, Charles IX relève que les arrière-bans de Bretagne sont « les principalles forces dudict pays ${ }^{189}$ ". De plus, il apparaît qu'en Bretagne, dans le contexte troublé des guerres de Religion, l'arrière-ban dispose d'une véritable capacité militaire. En effet, bien des situations délicates sont résolues grâce à la mobilisation des gentilshommes de la province. Mais il est vrai que le service tend à devenir une force essentiellement défensive. Pour faire face aux dangers maritimes et défendre les côtes, la monarchie n'a que très peu besoin d'unités régulières. Ainsi, l'arrière-ban revêt un caractère de défense du littoral, permettant conjointement aux compagnies d'ordonnance de pouvoir être mobilisées sur les principaux terrains d'affrontements et de prendre part aux campagnes de l'armée royale (centre et sud-ouest du royaume). En définitive, les réformes militaires du XVI ${ }^{\mathrm{e}}$ siècle ont permis à de nombreux petits nobles de continuer à pouvoir servir dans l'institution sans pour autant se ruiner en équipements militaires, cela dans une perspective d'entretien de l'idéal nobiliaire fondé sur le port et l'exercice des armes. Dans la même logique, l'accès au service pour les roturiers fut autorisé par le pouvoir royal, mais fortement contrôlé et limité. Mais à

186. Lettre de Henri III à Fontaines ou La Hunaudaye, 15 novembre 1585 (BnF, fr. 3309, $\left.f^{\circ} 73 v^{\circ}\right)$.

187. Jean du Breuil est nommé capitaine le poste étant « vacquant par le décès de Julien du Breuil sieur de Pontbriand son pere ", Nantes, 29 juillet 1587 (BnF, fr. 22340, f 202 v $^{\circ}$ ). 188. "Provisions de la charge de commissaire de l'arriere ban de l'eveché de Rennes données le $10^{\mathrm{e}}$ de decembre de l'an 1588 au sieur du Plessis d'Argentré, par le duc de Mercœur gouverneur de Bretagne, cet acte signé Philipe Emanuel de Lorraine " ; "Contract de mariage de noble homme Giles du Plessis, seigneur du Plessis d'Argentré, et commissaire de l'arriere ban de l'eveché de Rennes, acordé le 31 ${ }^{\text {e }}$ de juillet de l'an 1596 avec demoiselle Julienne de Grasmenil " (BnF, fr. 32121, f ${ }^{\circ}$ 176. Preuves de noblesse des demoiselles de Saint-Cyr).

189. Arch. dép. de Loire-Atlantique, B $56, \mathrm{f}^{\circ} 222 \mathrm{v}^{\circ}$. 
l'épreuve des guerres civiles, le bilan est tout autre. Les guerres de Religion marquent la fin des «mobilisations générales ». En effet, dès 1570, le pouvoir royal renonce aux convocations générales, ce qui se traduit par l'absence de mobilisation de certaines unités ou de certains secteurs, d'autant que le frein légal des trois mois maximum de service des feudataires constitue un handicap, même si ce temps n'est pas toujours respecté. Cependant les compagnies d'ordonnance étant stationnées en dehors de la province ou, au mieux, sur ses marches pendant les troubles, la partie effectivement mobilisée de l'arrière-ban apparaît comme le seul garant de l'ordre public. À ce titre, de nombreux nobles sont attirés par les charges de commandement, l'organisation de compagnies sert même à l'expression des clientèles nobiliaires. Si le cadre légal fut biaisé par la sélection des convoqués ainsi que par le prolongement du service pour certaines unités, le rôle social fédérateur de la noblesse reste d'actualité. Quand le danger est bien visible, c'est toute la noblesse du pays qui prend les armes et réussit - dans la majorité des cas - à repousser les envahisseurs ou à reprendre une ville surprise un temps. 


\section{RÉSUMÉ}

Dans la seconde moitié du $\mathrm{XvI}^{\mathrm{e}}$ siècle, le pouvoir central a dû organiser le maintien de l'ordre quotidien dans les provinces face au danger anglais, flamand, espagnol puis huguenot. Les gouverneurs ont eu à s'appuyer sur les forces militaires dont ils disposaient. En Bretagne, la faiblesse de l'armée royale permanente a redonné tout son sens stratégique à l'ancienne institution féodale du ban et de l'arrière-ban. L'ancien service d'ost dû au roi de France a en effet subi une vague de réformes et de législations au $\mathrm{XvI}^{\mathrm{e}}$ siècle qui en a fait une institution militaire à part entière. Face à la réalité des divisions confessionnelles, le service banal a dû s'adapter pour conserver son rôle de garant de l'ordre public tout en maintenant un certain idéal nobiliaire lié au service des armes. Quels sont les enjeux sociaux mais aussi politiques liés au port des armes du second ordre?

\section{ABSTRACT}

In the second half of the 16th century, central government had to maintain order on a daily basis in the provinces in the face of English, Flemish, Spanish and, later, Huguenot threats. Governors had to rely on their own military forces. The small number of royal soldiers permanently stationed in Brittany enhanced the strategic value of the old feudal institution of the ban and the arrière-ban. The earlier service d'ost owed to the king of France went through a series of reforms and legislative changes in the 16th century and was gradually turned into a proper military institution. In the context of religious division, the ban had to change to keep its role as the guarantor of law and order as well as retaining the noble ideal of military service. What are the social as well as political issues at stake when considering the matter of bearing weapons for the nobility? 